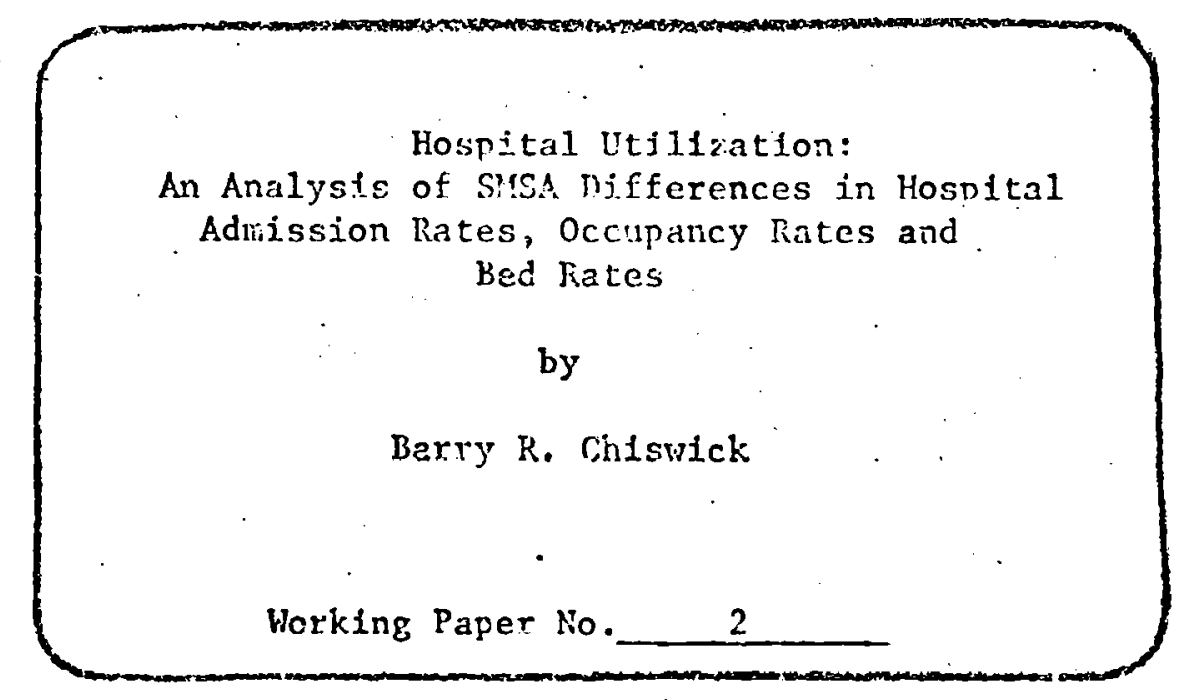

CENTER FOK ECONOMIC ANALYSIS OF IMNAN BEHAVIOR AND SOCIAL MiNSTITUTIONS National Bureau of Economic Research. Inc.

$261 \mathrm{Mad} 1$ son Avenue, New York, N.Y. 10016

June 1973

\title{
Preliminary; Not for Quotation
}

NBER working papers are distributed informally and in 11mted numbei for coments only. They should not be quoted without written permission.

Th1s report has not undergone the revlew accorded offlcial NBER mublications; in particular, it has not yet becn subintted for approval by the board of Directors. 
Hospital Utilization: An Analysis of SMSA Differences

In Occupancy Rates, Admission Rates and Eed Rates

Barry R. Chiswick

"... the national surpius of hospital beds

by no neans contradicts the fact that there

are frequent shortages in particular

cormunities at particular times."

(liew York Times, Editorial, August 26, 1971, p. 35). 
Hospital Ut11ization:

An Analysis of SMSA Differences

in Hospital Admission Rates, Occupancy

Rates and Bed Rates

Barry R. Chiswick

Table of Contents

Chapter I - Introduction and Summary

1. Introduction

2. Framework

3. Summary of Findings

Chapter II - The Theory

1. Introduction

2. Occupancy Rate

3. Admission Rate

4. Bed Rate

Chapter III - Empirical Analysis

1. Occupancy Pate

2. Admission Rate

3. Bed Rate.

Appendix A: Data Appendix

Appendix B: Additional Tables

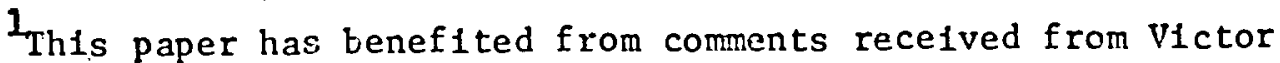
Fuchs and Michael Grossman, and at seminars at the National Bureau of Economic Research, the Graduate School, City University of New York, the Center for Health Aiministration Studies, University of Chicago, and the Health Services Administration, New York City. I also appreclate the research assistance of. Carol Breckner, Phyllis Goldberg and Janlce Platt. The project was financed by a grant to the NBER from the Naticral Center for Health Services kesearch and Development (Grant Rumber 5P01HS00451) and by the Industrial Relations Section, Princeton University. I alone am responsible for any errors of commission or omission. 
Chapter I

\section{Introduction and Summary}

\section{Introduction}

A topic of continued public concern is the national level and distribution among areas and individuals of the avallabilfty of hospital services. The New York Times in 1971 contained articles stressing the cost in terms of delayed treatment and death of insuficient hospital beds. ${ }^{1}$ During the same year, the Times carried articles indicating

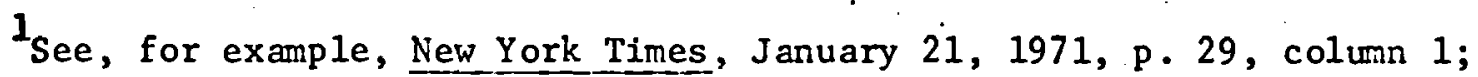
and September 12, 1971, section IV, p. 9, column 5 .

the cost to society of unused hospital teds. ${ }^{2}$

${ }^{2}$ For example, the Times reported Elliot Richardson, then Secretary of Health, Education and Welfare, as citing "an estimate of $\$ 3.6$ billion as last year's cost of maintaining unused beds all over the country." (New York Times, August 26, 1971, p. 36). Richardson's (urexplained) figure of $\$ 3.6$ billion may be contrasted with the $\$ 4$ billion in federai money spent for hospital construction under the Hill-Burton program since its inception 25 years ago. (New York Tines, November 23, 1972, p. 1 , column 1.)

Table I-1 presents data for the country as a whole on hospital utilization during the post World War II period for short-term non-federal hospitals. The bed rate ( the number of beds per thousand fopulation) Increased nearly 25 percent. The admission rate (admissions per thousand population) increased nearly 50 percent. The average bed occupancy rate 
Tab le $\mathrm{I}-1$

Utilizacion of Short Term General and Specialty non-Federal iospitals, 1946-1970

$\begin{array}{lcccc}\text { Year } & \begin{array}{c}\text { Bed } \\ \text { Rate }\end{array} & \begin{array}{c}\text { Admissicn } \\ \text { Rate }\end{array} & \begin{array}{c}\text { Occupancy } \\ \text { Rate } \\ \text { (Percent) }\end{array} & \begin{array}{c}\text { Length of } \\ \text { Stay } \\ \text { (Days) }\end{array} \\ 1946 & 3.4 & 96.6 & 72.1 & 9.11 \\ 1950 & 3.3 & 109.9 & 73.7 & 8.15 \\ 1955 & 3.5 & 115.6 & 71.7 & 7.78 \\ 1960 & 3.6 & 127.1 & 74.6 & 7.60 \\ 1965 & 3.8 & 136.2 & 76.0 & 7.77 \\ 1967 & 4.0 & 135.8 & 77.7 & 8.28 \\ 1968 & 4.0 & 135.9 & 78.2 & 8.45 \\ 1969 & 4.1 & 139.4 & 78.8 & 8.41 \\ 1970 & 4.1 & 142.8 & 78.1 & 8.26\end{array}$

Sources:: 1940 to 1960: Historical Statistics of the United States From Colonial Times to the Present, U.S. Bureau of the Census, 1965, Series A-1, B-198, 208, 251, 252 . 1965 to 1970: Statistical Abstract of the United States, 1972 , U.S. Bureau of the Census, 1972, Table Nos. 2, 104, 107.
$a_{\text {Bed }}$ Rate $=$ Beds per thousand population
${ }^{b}$ Adnission. Rate $=\Lambda$ dmissions per thousand population 
(the proportion of days in the year the average bed is occupied)

increased during most of the period, but has recently been on the decline. 1

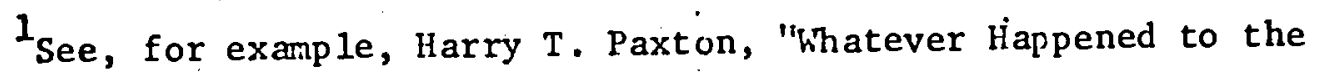
Hospital Bed Shortage?" Medical Economics, February 28, i973, p. 33.

These changes are important because hospitals do perform useful services, but at a considerable cost -- a cost which has been growing rapidly. ${ }^{2}$

2 The American Hospital Association reported that the daily cost of caring for patients in short-term general hospitals averaged $\$ 81$ in $1970, \$ 92$ in 1971 and $\$ 105$ in 1972. The cost has almost doubled from 1966 to 1972. (New York Times, July 31, 1972, p. 36, column 4, and Ianuary $15,1973, \mathrm{p} .23$, column 5.)

Although occupancy rates are declining nationally, regional maldistributions and political pressures still induce hospital bed construction. ${ }^{3}$

3he Government Accounting office reported the "overbuilding" of hospital facilities in six cities (New. York Times, December 18, 1972, p. 78, column 1). Congress still passes legislation to promote. hospital bed construction (New York Times, September 21, 1972, p. 36, column 1).

The purpose of this study is to present a-model (Chapter II) for analyzing the utilization of short-term general hospitals -- in particular, occupancy rates, admission rates, bed rates and length of stay. 
This model is then applied (Chapter III) to a cross-section analysis of regional differences in hospital utilization. The objective is to develop structural equations and hypotheses as to why the measures of hospital utilization vary across communities, and to estimate these equations and test these hypotheses. There 1s, however, an identity relationship between average length of stay $(\overrightarrow{\mathrm{LS}})$, and the occupancy rate $(O R)$, admission rate (Adns*) and bed rate (Beds*):

$$
O R=\frac{(\text { Adms } *)(\overline{\mathrm{LS}})}{(365) \mathrm{Deds} \mathrm{S}^{*}} \text {. Length of stay is the "redundant" }
$$

variable for the purpose of this study.

\section{Franeworl:}

The number of tospital admissions demanded in a year in a community is viewed as a declining function of the cost of such care. This relation, however, need not be the sane for all comiunities. For: example, the number of admissions demanded may be greater, the larger the number of surgeons and the more important is health insurance in the community. In addition, more strict rationing of admissions (and hence a smaller number of admissions) may occur when hospitals are very crowded.

The analysis of the supply of hospital admissions is based on both a short run and a long run model of hospital bed avallability. In the short run the bed rate (the number of beds per thousand population) is assumed to be fixed and determined by factors outside 
the model under investigation. If we assume a fixed bed rate (Beds*) and a constant length of stay (LS), the largest possible admission rate would be found by: Adms* $=\frac{(\text { Beds*)(365) }}{L S}$. In Figure I this is represented by the point at which the demand curve for admissions Intersects the supply curve of admissions and the number of admissions is $\dot{q}_{0}$.

However, this is an unrealistic view of the supply side of the short run model. The demand for hospital beds is not a constant daily quantity but rather a fluctuating one. It is higher on some days than on others. ${ }^{1}$ In the case of hospital care, the output cannot

1 This is true of all markets, and output or productive capacity tends to be "stored" by suppliers or demanders depending on the exteat of fixed costs and relative storage costs.

generally be stored by the consumer. ${ }^{2}$ This means that if on a given $\therefore$

"Preventive medicine may be viewed . . . as a means of "storing" health services.

day there is a greater demand for hospital beds than can be satisfied by the available supply and if non-price rationing is used, some consumers will have to delay (or forego) the satisfaction of their demand for hospital services even though they were willing to pay the current market price. Delayed satisfaction of demand for hospital care is not without cost, as anyone who has ever been in pain or discomfort or has ever faced death is well aware. Thus, a community would want to have 
Short-Run Supply And Demand

For: Hospltal. Adnissions

I Price

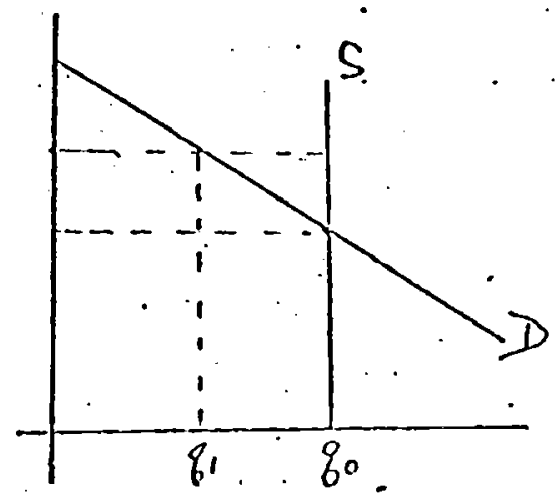

Number of Adinissions

Per Year

FIGURE II

Long-Run Supply And Demand For $\Lambda$ draisstons

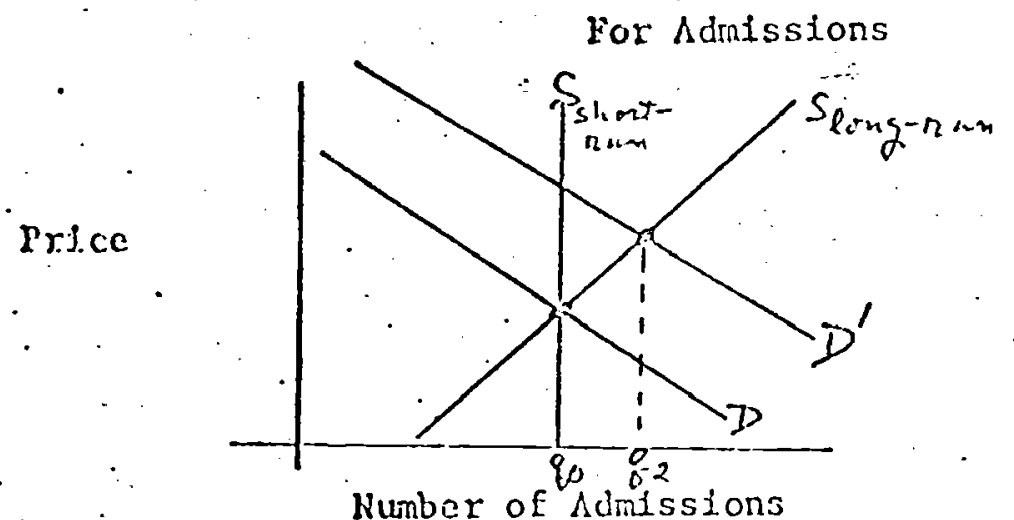

Per Year 
what appears to be excess capacity in hospital beds on the average day of the year, so that it could provide some additional in-hospital bed care during periods of high demand. 1

$1_{\text {This assumes that "at capacity" the marginal cost of admissions }}$ rises steeply. If the marginal cost of providing additional beds and ancillaxy services did not rise with the quantity supplied in the short run, there would be no economic demand for an "excess supply" on the average day.

A useful measure of "excess capacity" in a community is its average occupancy rate in a year. The average occupancy rate is measured by the ratio of the number of patient days (admissions multiplied by average length of stay in days) to the number of available bed days (the number of beds multiplied by 365 days) -OR $\approx \frac{\text { (Admissions)(Length of Stay) }}{\text { (Beds)(365) }}$. If, for example, the average' length of stay is five days, a community with 100 beds and an average bed occupancy rate of 90 percent accommodate: 6,570 admissions. $\left(q_{1}=\frac{\text { OR(Beds }) 365}{\text { LS }}=\frac{(0.90)(100)(365)}{5}=6,570\right.$ admissions. $)$ At a 100 percent occupancy rate it could accommodate this number of admissions with 90 beds, but more patients would have to be granted a delayed admission. A delayed (or denied) admission of a serious case is costly. More excess capacity on the average reduces the likelihood of the demand for beds exceeding the number of beds. However, constructing and maintaining excess capacity are costly. Thus, there is some desired average occupancy rate that is less than 100 percent. This is represented in Figure $I$ by a number of admissions equal to $q_{1}$, which is less than $q_{0}$. 
Hospital administrators have control over the occlipancy rate through their control of admissions and length of stay. If a lower occupancy rate is desired, they can be more selective in the cases that are admitted and thus decrease the admission rate and/or the average length of stay. The variables that are hypothesized to enter into the process of selecting the community's desired occupancy rate, given a fixed supply of beds, form the framework for the analysis of the occupancy rate equation.

- In sumnary, the short run includes a fixed supply of beds, a hospital adnission rate equation and an occupancy rate equation. Both equations are needed to determine the number of admissions and the occupancy rate in a community: a high admission rate causes a high occupancy rate, but a high occupancy rate causes a low admission rate.

In the long run; however, the bed rate (beds per thousand population) is not exogenous to the model. For example, if the demand for admissions is high relative to the number of beds, the occupancy rate is high. Some patients for whom the cost of a delayed admission is high do In fact experience a delayed admission in their community and must either postpone the hospital admission or seek such care elsewhere. The implicit value of an additional admission is now high. If communities respond to this high marginal value of admissions, the number of beds will be increased in the long run (see Figure II). ${ }^{1}$

$1_{\text {The supply response may come from the public sector, }}$ voluntary hospitals or proprietary hospitals. 
Our long run analysis. , relies on a two equation model: the admission rate is a function of the bed rate, and the bed rate is a function of the admission rate:

This study, therefore, focuses on three inter-related dependent variables: the admission rate, the occupancy rate and the bed rate. Chapter II presents the development of the three equations, one for each dependent variable $j$ and Chapter III presents the empirical estimation and interpretation of these equations.

The Standard Netropolitan Statistical Area serves as the unit of observation in the empirical analysis. ${ }^{1}$ SMSAs were selected for

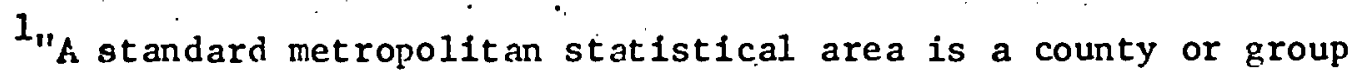
of contiguous counties which contains at least one city of 50,000 jnhabitants or more, or two contiguous cities with a combined population of at least 50,000. In New England, however, SMSA's consist of towns and cities rather than counties. Since town and city information is not available, the SASA's in New England have been replaced by metropolitan State economic areas, which are defined in terms of whole counties." (Hospitals: County and Metropolitan Area Data Book, National Center for Health Statistics, Department of Healtin, Education and Welfare, 1970.) For simplicity of exposition, non-New England SHSA's and New England metropolitan State eccnomic areas are referred to as SMSAs.

three reasons. ${ }^{2}$ First, SMSA borders are designed to represent population

2 To the author's knowledge, this is the first study of hospital utilization to use SMSAs as the unit of observation. Other studies for the United States have used individuals (microdata), hospitals in a particular geographic area, or states as the unit of observation.

centers and are clearly better suited for this purpose than city, county or state boundaries. It seems reasonable that this is also true 
for health regions. Potential patients, doctors and hospital administrators are presumably concerned more with "reasonable commutation distances" than with city or county boundaries. 1 While SMSAs may not

${ }^{1}$ Eor example, Santa Monica, Culver City and San Fernando are three cities in Los Angeles county surrounded by Los Angeles city. Yet these separate cities do not appear to constitute separate health communities as there is considerable mobility across city boundaries. At the other extreme are the five counties which compise New York City. The large proportion of residents who seck hospital services outside of their own county sugiests that the populace acts as if the city represents a single medical center. States were not used as the unit of observation because for many states either there are two or more hospital areas between which there is little mobility, or there is commutation across state borders for the purchase of hospital care.

be ideal candidates for health regions, they are reasonably good approximations. Second, the data needed for this study are generally available: on an SMSA basis. ${ }^{2}$ Third, by using SMSAs we obtain a sufficientiy

2 The data for hospital utilization are from a 1967 survey of all short term general hospitals in the country. (Hospitals: a County and Metropolitan Area Data Book, National Center for Health Statistics, Department of liealth, Education and Welfare, November 1970.) For a discussion of these and the other variables, see Appendix A.

large sample, 192 observations. 
for health reglons. Potential patients, doctors and hospltal administrators are presumably concerned more with "reasonable commutation distances" than with city or county boundarles. ${ }^{1}$ While SMSAs may not

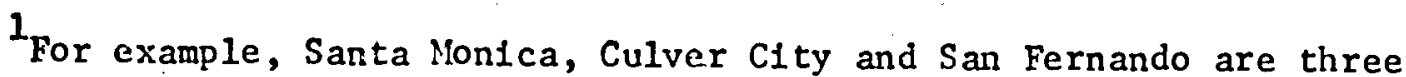
cities in Los Angeles county surrounded by Los Angeles city. Yet these separate cities do not appear to constitute separate health communities as there is considerable mobility across city boundaries. At the other extreme are the flve counties which comprise New York C1ty. The large proportion of residents who seek hospital services outside of their own colnty sugeests that the populace acts as if the city represents a single medical center. States were not used as the unit of observation because for many states efther there are two or more hospital areas between which there is little mobility, or there is commutation across state borders for the purchase of hospital care.

be Ideal candidates for health regions, they are reasonably good approximations. Second, the data needed for this study are generally avallable on an SNSA basis. ${ }^{2}$ Third, by using SMSAs we obtain a sufficientiy

The data for hospltal utilization are from a 1967 survey of all short term general hospitals in the country. (Hospitals: a County and Metropolitan Area Data Book, National Center for Health Statistics, Department of Health, Education and Welfare, November 1970.) For a discussion of these and the other variables, see Appendix A.

large sample, 192 observations. 


\section{Summa ry of Findings}

This study analyzes SMSA differences in the utilization of shortterm general hospltals by explicitly examining three dependent (endogenous) variables: the occupancy rate, adnission rate and bed rate.

Our analysis of SMSA differences in occupancy rates is based on the randonness of the demand for admissions. Since the demand for admisstons fluctuates, the populace and hospital planners in an SMSA are concerned with maintaining an average occupancy rate sufficiently less than 100 percent so as to have an optimal probability that someone desiring an admission will be turned away because the hospitals are at full capacity. It is estimated that under 1967 utilization Jevels the demand for beds in an SMSA would exceed the supply of beds (on average) In only one week out of 12.8 years.

The empirical analysis strongly supports the predictions of the randomness nodel for occupancy rates. SMSA with higher admisston rates have higher occupancy rates. More populous SNiSAs are better able to take advantage of their smaller relative fluctuations in demand for admissions, and maintain a higher occupancy rate. When there are more hospitals for the same number of beds (and hence the hospitals are smaller), there is a lower occupancy rate. The larger number of hospitals reduces the substitutability among hospital beds, because of a poorer "referral" system between hospitals than within hospitals.

Higher occupancy rates could be obtained by reducing the barriers between hospitals. These barriers include the limited number of hospital affiliations had by most physicians, the required veteran status for entry into federal hospitais, the provision of charity hospitaliza- 
tion primarily by public hospitals, and hospitals restricted to particular demographic (age, sex, etc.) groups.

Occupancy rates are higher in SMSA $\widehat{\sim}$ sith colder winter climates and a larger proportion of nonwhites in the population. These effects are presunably due to longer lengths of stay.

The analysis of hospital admission rates looks at variables which have been hypothesized to effect the height of the demand for, or the price of, a hospitalization. Then hospitals are moze crowded (high occupancy rate), the admission rate is lower because hospital administrators are more selective in the cases that are admitted in order to reduce the probability of capacity utilization. In addition, admission ratesare higher, the more important is hospital and surgical insurance and the more numerous are surgeons in the SMSA's population. ${ }^{1}$ The relative numier of non-surgical physicians has no effect on the admission rate. Admission rates are also higher, the lower the median family income (elasticity at mean $=-0.78$ ), the more numerous are nonwhites in the population, and the colder the winter climate. The effect of nonwhites on admissions may be due to the poorer level of health of nonwhites.

Our third dependent (endogenous) variable is the bed rate. A 10 percent increase in the bed rate results in a 2 percent decrease in the occupancy rate, a 4 percent increase in the average length of stay and a 4 percent increase in the admission rate. This largely supports

$1_{\text {It }}$ is not clear to what extent a larger relative number of surgeons is a cause or a consequence of a greater demand for hospitalization. 
Roemer's Law that an increase in beds resulits in these beds being filled with little change in the occupancy rate. It is, however, noteworthy that a 10 percent increase in admissions increases the number of beds by 9 percent. Thus, the effect of admissions on beds is stronger than the effect of beds on adrissions.

Our model for the randomness of demand for admisslons suggests several other varlables as relevant for an analysis of the demand for hospital beds. Two of these variables, population size and the number of hospitals, have no signiflcant effect empirically. Three other variables, the proportion of beds in federal hospitals, the emergency death rate and median family income, do have an effect.

Beds in federal hospitals are found to be imperfect substitutes for beds in non-federal hospitals presumably because of the required veteran status in the former. The presence of, say, a 130 bed federal hospital In an SliSA with a milion inhabitants decreases the number of nor-iederal beds in the SMSA by approximately 40 beds. The more important are emergencies in an SMSA's case mix, the greater is the expected cost of a delayed admission because of capacity utilfzation, and hence the greater is the SMSA's demand for beds. The positive effect of income on the bed rate (elasticity at the mean $=+0.12$ ) is consistent with the by pothesis that wealthier SISA s buy more excess capacity than poorer SMSAs through the construction of more beds.

- There is an interesting relation between the relative number of nonwhites in the population and hospital ut1lization. SMSA $\hat{\text { s }}$ with relatively more nonwhites have higher admission rates and a longer average length of stay, but there is no compensating difference in the 
bed rate. The result is greater hospital crowding and a greater probability that a desired admission will be delayed (or denied) the larger the relative number of nonwhites in the population. 1

Our theoretical and empirical analyses of hospital occupancy rates, admission rates, bed rates and length of stay indicate that these statistics vary across SMSA and that this variation can be related systematically to the characteristics of the SMSA.

However, the data used in this study do not permit an identification of racial differences in the delay of admission (case mix constant) within SMSAs. 
CHAPTER II

\section{The Theory}

\section{Introduction}

This chapter presents the theoretical analysis by which we errive at the hypotheses and structural equations for the three dependent variables examined in this study: the admission rate, the occupancy rate and the bed rate. The equations should not be estimated by ordinary least squares (single equation) techniques. In our short run model, the occupancy rate is determined simultaneously with the admission rate since each affects the other. In our long run model, the bed rate (beds per thousand population) and the admission rate are mutually determined.

Part (2) of this chapter presents the development of the hospital occupancy rate equation. A model based on the randomness of admissions suggests that the occupancy rate in an SMSA is related to the admission rate, population size and number of hospitals. This forms the basis of the analysis of occupancy rates, and proxy variables are entered in some of the analysis to control for SMSA differences in length of stay.

The admissions equation is developed in part (3). The demand for admissions is assumed to be greater; the lorver the price of an admission, or the easier the non-price rationing by hospitals. Thus, hospital and surgical insurance, the presence of physicians, the occupancy rate and the number of hospital beds are shown to enter the admissions equation. Other variables, mainly to hold constant demographic differences across SMSAs, are Included. 
In Part (4) the bed rate (beds per thousand population) equation is presented. The equation is developed under the assumption that it represents

long run supply. The model for the randomness of admissions suggests that the admission rate, the demand for emergency care, the size of the population and the number of hospitals are explanatory variables.

\section{Hospital Occupancy Rates: ${ }^{1 /}$}

$1 /$ The occupancy rate of a region is the total number of patient days in a period of time (e.g., a year) divided by the product of the average number of beds and the number of days in the time period. Bed occupancy rates can be greater than $100 \%$ if some beds (e.g.; temporary beds in passageways) are not counted in the bed census but their occupants are counted in the total number of patient days.

\section{A. Introduction:}

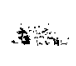

The average occupancy rate in short term general hospitals in an

area is neither constant nor purely random. It may be

determined by the economic and institutional characteristics of the community.

The purpose of this section is to develop a structure which will be used to obtain hypotheses concerning regional differences in occupancy rates.

The maintenance of a hospital bed and its auxiliary equipment and personnel is costly. A bed is productive when it is occupied. This does not mean, however, that average occupancy rates of less than 100

percent represent wasted resources. If there were a known constant number of beds demanded each day for each hospital, ' occupancy rates less than 100 percent would indeed represent wasted resources. However, since there are fluctuating demands for hospital services, the presence of "excess capacity" on the average day is efficient. That is, up to a point, vacant beds are a productive resource. The extent to which occupancy rates do 
In fact respond to fluctuations in admissions is a major aspect of our analysis of occupancy rates. 1

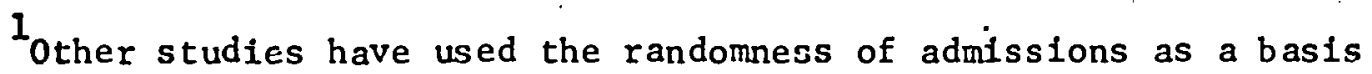
for analyzing hospital occupancy rates. See, for example, Hyman Joseph and Sherman Folland, "Uncertainty and Hospital Costs," Southern Economic Journal, October 1972, pp. 367-73; Hilliam Shonick, "A Stochastic Model for Occupancy Related Random Variables in General-Acute Hospitals," Joumal of the American Statistical Association, December 1970, pp. 1474-1500; M. Long and P. Feldstein, "Economics of Hospital Systems: Peak Loads and Regional Coordination," American Economic Review, May 1967, pP. 119-129, and references therein. This study differs from the others in terms of (1) the specification of the randomess model (including the effects of population size and number of hospitals), (2) treating the admissions variable as endogenous rather than exogenous, and (3) the application of the model to regional differences in hospital utilization rather than to hospital differences within an area.

\section{B. Fluctuating Demands}

The rate of admission $(p)$ is the number of admissions in a time period, $N$, divided by the size of the population (pop). That is, $\mathrm{P}^{+}=\mathrm{N} / \mathrm{pop}$. Etther an individual is a hospital admission or he is not. Using the binomial theorem, the variance across time periods in the number of hospital admissions is $\operatorname{Var}(\mathrm{N})=(\mathrm{pop}) \mathrm{p}(1-\mathrm{p})$.

The number of patient days (PD) of hospital care in a time period is the sum across patients of all of the lengths of stay (LS) within that time period. - It can be thought of as the average length of stay $(\overline{\mathrm{LS}})$ multiplied

If If we know the number of hospital beds (B), the number of admissions in a time period (N), the length of the time period (D) and the occupancy rate (OR), by a simple identity we know the average length of stay. [LS = (OR) (D) (B).]

In this study length of stay is viewed as the redundant variable, and ${ }^{N}$ the analysis focuses on the occupancy rate, the bed rate and the admission rate. For simplicity of presentation of the randomness model, the average length of stay is assumed constant across time periods. 
by the number of admissions (N). If $\overline{\mathrm{LS}}$ does not vary across time periods, the variance in patient days can be written as. $(I I-1) \quad \operatorname{Var}(P D)=(\overline{L S})^{2}(p \circ p)(p)(1-p)$.

The expected number of patient days is (I.I-2) $\quad E(P D)=E(\overline{\mathrm{LS}} \mathrm{N})=\overline{\mathrm{LS}}(\mathrm{pop})(\mathrm{p})$.

The coefficient of variation in patient days is (II-3) $\quad \mathrm{CV}(\mathrm{PD})=\frac{\mathrm{SD}(\mathrm{PD})}{\mathrm{E}(\mathrm{PD})}=\frac{\overline{\mathrm{LS}} \sqrt{\mathrm{pop}(\mathrm{p})(1-\mathrm{p})}}{\mathrm{LS} \text { pop } \mathrm{p}}=\sqrt{\frac{1}{\mathrm{pOp}} \frac{(1-\mathrm{p})}{\mathrm{p}}}=\sqrt{\frac{1}{(\mathrm{pOp})}}\left(\frac{1}{\mathrm{p}}-1\right)$. The relative variation in patient days in a time period is smaller, the 
larger the size of the population, and the greater the rate of admission. 1 /

1/ Similar conclusions emerge if length of stay (LS) is not considered constant over time. Let us assume that across time perlods (1) the average length of stay and the number of admissions are independent.

(a) $\operatorname{Var}(P D)=\operatorname{Var}\left(\mathrm{IS}_{i} \cdot \mathrm{N}_{i}\right)=(\overline{\mathrm{LS}})^{2} \operatorname{Var}(\mathrm{N})+\overline{\mathrm{N}}^{2} \operatorname{VAR}(\mathrm{LS})+\operatorname{Var}(\mathrm{ISS}) \operatorname{Var}(\mathrm{N})$, if $\mathrm{LS}_{i}$ is independent of $\mathrm{N}_{i}$

Then, since

(b) $\operatorname{Var}\left(\mathrm{N}_{i}\right)=(\mathrm{pop}) \mathrm{p}(1-\mathrm{p})$ and $\overline{\mathrm{N}}=$ (pop) $\mathrm{p}$.

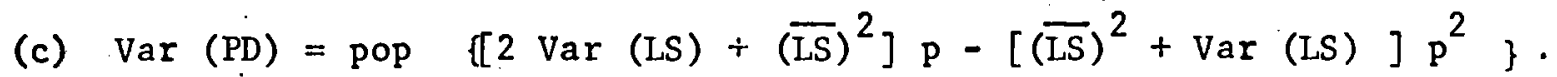

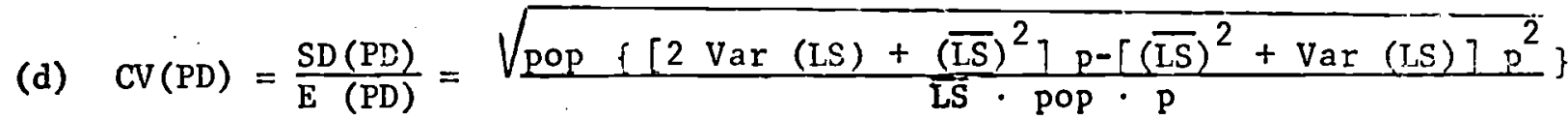

and

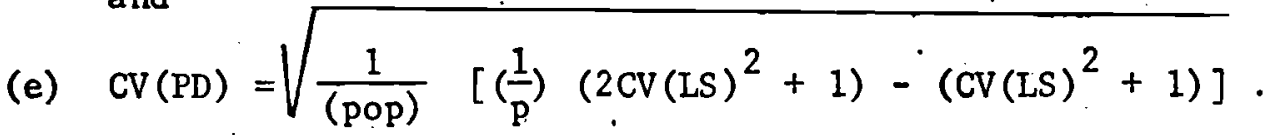

CV(PD) is negatively related to population size and the rate of admission, and positiveiy related to the coefficient of vartation of length of stay across time periods. These relationships would hold even if length of síay were not statistically independent of the admission rate, although the equation would ie far more complicated. See Lco Goodman, "On the Exact Variance of a Product," Journal of the Arierican Stat1stical Association, December 1960, pp. 708-713.

Let us assume that the mean and standard deviation of the nimber of patient days that will be demanded in a time period in a community were known. If the demand for an admission by one individual were Independent of that of others, the demand for patlent days would be normally distributed. ${ }^{2}$ Then, if the community wishes to have

2/ Annual rates of adalission are about 15 percent. Assuming independence of individual admissions, the distribution of admissions for, say, a week approxlmates the Poisson Distribution for a small sample (e.g., a household or a small work group), but approximates a normal distribution for a large sample (e.g., a large factory, census tract or SMSA). For a binomial distribution, if the proportion of successes [in this case the admission rate (p) multiplied by the sample size (pop)] exceeds 10 , 
the number of successes (admissions) approximates a normal rather than a Poisson distribution. For a population of 100,000 and a weekly admission rate of $.15 / 52$, admissions $=(100,000) \cdot\left(\frac{.15}{52}\right) \approx 300$ and

the normal distribution is a close approximation to the binomial distribution.

beds to satisfy demands for admissions for, say, 97.5 percent of the time, the number of beds should exceed the mean number of patient days by approximately twice the standard deviation of patient days. 2 /

2/ This assumes perfect pooling of beds among the hospitals in the community. The effects of a lack of perfect pooling among hospitals in an area and the time lag in filling a vacant bed are discussed below. For the normal distribution only 2.5 percent of the observations are more than $1.96 \simeq 2.00$ standard deviations above the mean.

Let us assume there is no cost in shifting patients within the time period of $D$ days. Of course, $D$ may be one day. Let us designate $\mathrm{Z}_{\alpha}$ as the standardized normal variate which indicates that the number of beds is sufficient for all but $100 \alpha$ percent of occurrences. Then the number of beds in the community is

$(I I-4)_{B}=\left[E(P D)+z_{\alpha} \operatorname{SD}(P D)\right] \frac{1}{D}$.

That is, for only $100 \propto$ percent of occurrences will the number of patient days demanded in the time period of $D$ days exceed $E(P D)+z_{\alpha} S D$ (PD). Then, $(I I-5) \frac{B \cdot D}{E(P D)}=1+z_{\alpha} C V(P D)$.

The expected bed occupancy rate (OR) equals $\frac{E(P D)}{(B)(D)}$, if the number of beds is assumed fixed. Then, $(\mathrm{II}-6) \quad \mathrm{OR}=\frac{\mathrm{E}(\mathrm{PD})}{(\mathrm{B})(\mathrm{D})}=\left(\frac{1}{1+\mathrm{z}_{\alpha} \mathrm{CV}(\mathrm{PD})}\right)$. 
Taking natural $\operatorname{logs}$ and using the relation that $\operatorname{Ln}(1+a) \approx a$ when $a$ is sma11, $1 /$

$1 /$ For a population of one million, a daily admission rate of $\frac{.15}{365}$, and and $\alpha=.001$ (i.e., an insufficient number of beds for one-tenth of one percent of occurrences, or $\left.z_{\alpha}=3.0\right), z_{\alpha} \operatorname{cV}(\mathrm{PD})=z_{\alpha} \sqrt{\frac{1}{\mathrm{pop}}\left(\frac{1}{\mathrm{p}}-1\right)}=0.22$. If the pooling is done over a week, $\mathrm{Z}_{\alpha} \mathrm{CV}(\mathrm{PD})=0.084$. These values of $\mathrm{Z}_{\alpha} \mathrm{CV}(\mathrm{PD})$ are sufficiently small for the approximation to apply.

(II-7) LnOR $=-\left(\mathrm{Z}_{\alpha}\right) \mathrm{CV}(\mathrm{PD})$.

Combining equations (3) and (7), (II-8) $\operatorname{Ln}(\mathrm{OR})=-2\left(\sqrt{\left.\frac{1}{\mathrm{rop}}\left(\frac{1}{\mathrm{p}}-1\right)\right)}\right.$.

The occupancy rate is positively related to the size of the population, to the rate of admission, and to the proportion of occurrences for which the demand exceeds the number of beds $(\alpha) . \underline{2} /$ This provides us

$2 /$ The parameter $z_{\alpha}$ is smaller, the larger is $\alpha$. Hence, the larger is $\alpha$, the larger is LnOR.

with two measurable explanatory variables for inter-SMSA differences in occupancy rates: population size and admission rate.

\section{Communities may}

differ in their desired $\alpha$. If all admissions are "discretionary" [i.e, the cost of a delayed admission is low], the community would be willing to accept a larger number of instances in which the admission of potential patients is either denied or delayed. $\underline{\text { / }}$ if all admissions are "emergencies " [i.e., 
$3 /$ The costs of a delay include the extra foregone productivity of the patient, the extra psychic pain or death, ard the additional curative costs due to the delay. The benefits of delay include possibly a reduction in curative costs (e.g., due to naturaí healing) and a smaller average "excess capacity" of hospitals.

the cost of a delayed admission is high], the community would want a lower frequency of occurrences in which admissions are delayed or denied. Holding the admission rate constant, the effect of a differential emergency rate across SMSAs would operate in the Iong run through the number of beds per capita. SMSAswith more emergencies in their case load would have a higher bed rate and, as a consequence, achieve the objective of a lower occupancy. rate.

\section{Occupancy Rate Versus Use Rate}

The annual cccupancy rate of a hospital bed is the sum of the days in a year in which a patient is assigned to and using the bed divided by 365 days. When a bed is vacated, it is not always immediately reoccupied by another patient even if there is queuing for beds. The bed may be vacated too late in the day for the next patient to arrive, or the bed may be reserved for a day or two for a patient who is expected to arrive. ${ }^{1}$ The

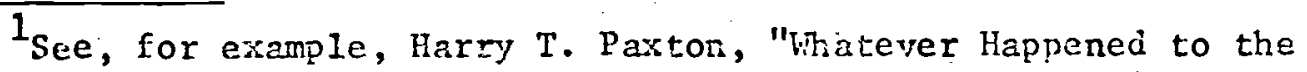
llospital Bed Shortage?" Medical Economics, February 28, 1973, p. 42. "use rate" of a hospital bed shall be defined as the occupancy rate plus the proportion of days of potential occupancy lost because of a late discharge or because the bed is being reserved. Data on bed use rates do not exist. However, the concept of "use" without occupancy may influence the relation between the admission rate and the occupancy rate.
}

The total number of bed days "used" in an SMSA in a year is the sum of the bed days of occupancy and the bed days consumed by lags between 
$3 /$ The costs of a delay include the extra foregone productivity of the patient, the extra psychic pain or death, ard the additional curative costs due to the delay. The benefits of delay include possibly a reduction in curative costs (e.g., due to naturai healing) and a smaller average "excess capacity" of hospitals.

the cost of a delayed admission is high], the community would want a lower frequency of occurrences in which admissions are delayed or denied. Holding the admission rate constant, the effect of a differential emergency rate across SMSAs would operate in the long run through the number of beds per capita. SMSAs with more emergencies in their case load would have a higher bed rate and, as a consequence, achieve the objective of a lower occupancy. rate.

\section{Occupancy Rate Versus Use Rate}

The annual cccupancy rate of a hospital bed is the sum of the days in a year in which a patient is assigned to and using the bed divided by 365 days. When a bẹ is vacated, it is not always immediately reoccupled by another patient even if there is queuing for beds. The bed may be vacated too late in the day for the next patient to arrive, or the bed may be reserved for a day or two for a patient who is expected to arrive. 1 The

${ }^{1}$ See, for example, Harry T. Paxton, "Whatever Happened to the llospital Bed Shortage?" Medical Economics, February 28, 1973, p. 42. "use rate" of a hospital bed shall be defined as the occupancy rate plus the proportion of days of potential occupancy lost because of a late discharge or because the bed is being reserved. Data on bed use rates do not exist. However, the concept of "use" without occupancy may influence the relation between the admission rate and the occupancy rate.

The total number of bed days "used" in an SMSA in a year is the sum of the bed days of occupancy and the bed days consumed by lags between 
successive occupancies. That is,

(II-9) Use $=($ admissions $)\left(\begin{array}{l}\text { length of stay } \\ \text { per admission }\end{array}\right)+($ admissions $)\left(\begin{array}{l}\text { lag in filling a } \\ \text { bed per admission }\end{array}\right)$.

We obtain the use rate (UR) by dividing both sides of equation (II-a) by (365) (Beds), (II-10) $U R=\frac{\text { Use }}{(365)(\text { Beds })}=\mathrm{OR}+\frac{\text { (admissions) }(1 \mathrm{ag})}{(365)(\text { Beds })}$, since $O R=\frac{\text { (admissions) (length of stay per admission) }}{(365)(\text { Beds) }}$

Designating the average lag per admission per bed day as $\ell=\frac{1 \mathrm{ag}}{(365)(\text { Beds) }}$, since admissions $=(p)(p o p)$,

(II-11) UR $=\mathrm{OR}+\ell \mathrm{P}$ (pop).

At full capacity the use rate is unity. Differentiating equation (1?) with respect to the admission rate when the hospitals are operating at full capacity, $(I I-12) \quad \frac{\partial U R}{\partial p}=\frac{\partial O R}{\partial p}+\left(\frac{\partial g}{\partial p}+\ell\right) p o p=0$

Thus, at full capacity $(U R=1.0)$, the marginal effect of admissions on the occupancy rate is.

(II-13) $\frac{\partial O R}{\partial p}=-\ell\left(1+\epsilon_{\ell, p}\right)(p o p)$ where $\epsilon_{\ell, p}$ is the elasticity of the lag per admission ( $(l)$ with respect to the admission rate. If the lag exists $(\ell>0)$ but is invariant with respect to admissions $\left(\epsilon_{\ell, p}=0\right)$, at full capacity the measured cccupancy rate will be less than unity, and a higher admission rate implies a lower occupancy rate. As long as the elasticity of the lag with respect to admissions is larger in algebraic value than minus unfty (i.e., $-1<\varepsilon_{\ell_{p}}$ ), occupancy rates decrease with an increase in admissions at full capacity (UR $=1.0$ ). 
Thus, the effect of the adnission rate on the bed occupancy rate is expected to be positive for utilization at less than full capacity, but it may be negative at or near use rates equal to unity: Since high occupancy rates may Imply capacity utilization, the admission rate may have a negative effect on occupancy rates at very high levels of occupancy.

\section{Bed Rate}

If an SMSA experiences an increase in its bed rate (beds per thousand population), and the SMSA's admission rate and average length of stay remain constant, the occupancy rate will fall. $1 /$ The exogenous increase in the bed

$1 /$ Recal1 that, since $\mathrm{OR}=\frac{(\mathrm{N})}{(365) \text { (LS) }}$ Beds,$\frac{\partial \mathrm{LnOR}}{\text { dLnBeds }}=-1$.

rate also tends to increase the admissjon rate. Therefore, SMSAs with larger bed rates may have higher admission rates and lower occupancy rates. $2 /$ If

$\underline{2}$ The effect of an increase in the bed rate on admission and occupancy rates is refarred to in the literature as "Roemer's Law". Roemer's Law says that exogenous increases in bed rates affect primarily admissions and lensth of stay; and leave occupancy rates virtually unchanged. That is, patients fill the available supply of beds. (For example, see M.I. Roemer and 11 . Shain, Hospital Utilization Under Insurance, Hospital Monograph Series, No. 6, Chicago, American Hospital Association, 1959). $\longleftarrow-$ The coefficient of variation of occupancy rates across SMSAs is considerably smaller than the coefficient of variation in admission rates and bed rates. (See Appendix A.)

the bed rate is not held constant in the occupancy rate equation, we could observe a negative partial effect of admissions on occupancy rates. The bed rate is hypothesized to have a negative effect on the occupancy rate.

\section{E. Cormunication Among Hospitals}

Suppose two communties have the same population, admission 
rate and desired $\alpha$. The communities differ in that Community $A$ has one hospital $\left(H_{A}=1\right)$, whereas Community $B$ has $k$ identical hospitals $\left(H_{B}=k\right)$, each servirg $\left(\frac{1}{k}\right)(100)$ percent of the population, with no communication of vacancies among hospitals. It can be shown that community $B$ is expected to have more beds and a lower occupancy rate.

By substituting equation (3) into equation (4), for community $A$, $(I I-14) B_{A}(D)=E(P D)(1+Z C V(P D))=E(P D)\left(1+Z \sqrt{\frac{1}{p o p}\left(\frac{1}{p}-1\right)}\right)$. For Community B,

$$
\begin{aligned}
(I I-15): B_{B}(D) & =k\left\{\frac{E(P D)}{k}\left(1+Z \sqrt{\left.\frac{1}{\frac{p o p}{k}}\left(\frac{1}{p}-1\right)\right)}\right\}\right. \\
& =E(P D)\left(1+(\sqrt{k}) Z \sqrt{\left.\frac{1}{p o p}\left(\frac{1}{p}-1\right)\right)}\right.
\end{aligned}
$$

where $k>1$. Th:1s, $B_{B}$ is larger than $B_{A}$.

Resall that equation (8) was;

(II-16) IJnOR

$$
=-z \sqrt{\frac{1}{p o p}\left(\frac{1}{p}-1\right)}
$$

Therefore, for Community B,

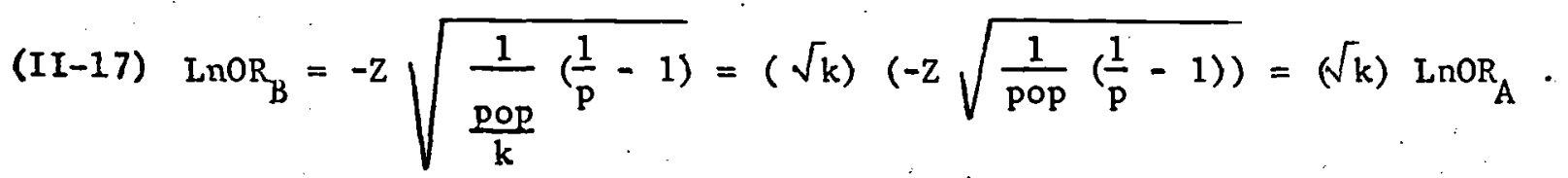

Since the natura ${ }^{\circ} \log$ of a number smaller than unity is negative and since $\mathrm{OR}_{\mathrm{A}}<1.0, \mathrm{OR}_{\mathrm{B}}^{\circ}<1.0$ and $\mathrm{k}>1$,

(II-18) $\left\{\begin{array}{c}\operatorname{LnOR}_{\mathrm{B}}<\mathrm{LnOR}_{\mathrm{A}}, \text { or } \\ \mathrm{OR}_{\mathrm{B}}<\mathrm{OR}_{\mathrm{A}}\end{array}\right.$

That is, ceteris paribus, because of less efficient pooling of beds, occupancy rates are lower in SMSAs with more hospitals. 
If a bed in one hospital were a perfect substitute for a bed in another hospital, the number of hospitals would have no effect on the bed rate or the occupancy rate. Thus, holding the bed rate and admission rate constant the inclusion of a variable for the number of hospitals in an analysis of occupancy rates tests for the lack of perfect substitution of beds among hospitals.

\section{F. Demoraphic Control Variab1es}

Holding constant the admission rate and bed rate, the occupancy rate is, by definition, a function of the average length of stay. The average length of stay. is a function of the SMSA's case mix and the demographic structure of the population. Although case mix data cannot be included, some of the empirical analysis does control for demographic variables. These variables include the sax, age, and race distributionsof the population, the live birth rate and the rate of growth of the population.

There is evidence that nonwhites have a longer average length of stay than whites. $1 /$ This suggests that, ceteris paribus, occupancy rates are

$1 /$ For example, in New York City the average length of stay of a white person is shorter than that of a black person, in spite of the younger average age of blacks. Average Length of Stay in Days

$\begin{array}{llll} & 1964 & \underline{1966} & \underline{1968} \\ \text { white } & 10.9 & 11.2 & 13.4 \\ \text { Black } & 13.2 & 11.6 & 14.5 \\ \text { Puerto Rican } & 14.2 & 12.6 & 15.0\end{array}$

Source: Donald G. Hay and Morey J. Wontman, "Fstimates of Hospital Episodes and Length of Stay, New York City, 1968", February 1972, mimeo.

higher in SMSA'S with a greater proportion of the population nonwhite. More rapidly growing SMSA? are hypothesized to have a lower occupancy rate 
because of a shorter length of stay. The shorter length of stay may be due to both the better health of migrants, and the greater attractiveness to migrants of healthier environments.

\section{G. Climate}

Thus far the analysis has assumed that the variables under study do not vary systematically over the year. Given an admission, however, climate may affect the length of stay. ${ }^{\prime} /$ It seems reasonable to hypothesize that,

$1 /$ The effect of seasonality on admissions is examined explicitly in the admission rate equation.

holding the admission rate constant, SMSAs in colder winter climates have longer lengths of stay for two reasons. First, since admission rates are higher in colder winter climates, $2 /$ for two SMSAs with the same admission

$2 /$ See; this monograph, chapter III, part 2 .

rate, the case mix is expected to be more heavily weighted towara more serious cases in the SMSA with the lower mean January temperature. More serious cases have longer average lengths of stay. Second, holding case mix constant, patients are likely to be kept in the hospital longer, the less amenable is the non-hospital environment to recuperation. Non-hospital care is presumably less productive than hospital care for recuperative purposes in a colder winter climate than in a warmer climate. Since longer lengths of stay increase the occupancy rate, holding the admission and bed rates constant, the partial effect of mean January temperature on occupancy rates is hypothesized to be negative. 


\section{H. Summary}

Table II-1 contains the regression equation for the occupancy rate analysis. If hypotheses as to the sign of a variable have been presented above, the sign is indicated.

All but one of the explanatory variables may be viewed in the short run as being "caused" independently of the dependent variable, LN(OR). The one exception is the admission rate ( $p)$. The admission. rate is, in part, a function of the occuparcy rate. At high levels of hospital occupancy, the cost to society of admitting a patient to fill a bed is the sum of the resources consumed because the bed is occupied plus a measure of the cost because a potential patient is denied access (or is granted delayed access) to a bed. This latter cost component does not exist when occupancy rates are low. Thus, we expect admissions to be more selective when occupancy rates are high. 1 /

1/For a time series study see John Rafferty, "Patterns of Hospital Use: An Analysis of Short-Run Variations," Journal of Political Economy, January/ February 1271, pRe 154-165.

$\longleftrightarrow$ It is for this reason that it is appropriate to use a predicted rather than the observed admission rate in the occupancy rate analysis. The next section develops an enuation with the admission rate as th.e dependent variable. In the empirical analysis the occupancy rate and admission rate equations are estimated simultaneously. 


\section{Occupancy Rate Equation ${ }^{\text {a }}$}

\section{Dependent Variable: The Natura1 Log of the Occupancy Rate (LnOR)}

Name

(1) Admission Rate
Predicted Sign of Slope

+ in "randomness model"

- in "lag mode1" when near $100 \%$ use rate

(2) Bed Rate

Beds*

(3) Square root of inverse of population

$$
\sqrt{\frac{1}{p O P}}=S P O P
$$

(4) Square root of number

(5) Percent Nonwhite of hospita $1 \mathrm{~s}$

$\sqrt{\text { Hosp }}$

\%NWHT

. .
Population
(6) Percent Change in Mean January Temperature

JANTEYP :

(8) Age, Sex Distribution

For a more detailed definition of the variables and data sources, see Appendix A. 


\section{Admission Rate}

Economic, demographic and institutional variables are used in this section to generate a model to explain SMSA differences in the rate of admission to short term general hospitals.

\section{(A) Hospital Occupancy Rate}

Hospitals appear to be more selective in the cases they admit when beds are scarce than when vacant beds are abundant. Medical conditions for which delay in treatment or alternative treatments are less costly are put lower down on the admissions queue during periods of high occupancy rates. To the extent that higher occupany rates increase the delay before a desired admission can take place, alternative sources of medical treatment (including spontaneous cures) or death may reduce the total rimber of actual admissions. Alternative sources of medical treatment include home care, specialized hospitals, nursing homes, and hospitals outside of the SMSA. Thus, we expect a negative partial effect of the occupancy rate on the admission rate.

\section{(B) Bed Rate}

An alternative hypothesis (Roemer's Law) is that communties malntain a constar occupancy rate and admissions and length of stay are a function of the number of beds in the SMSA. (1) To test a "beds effect" on admissions,

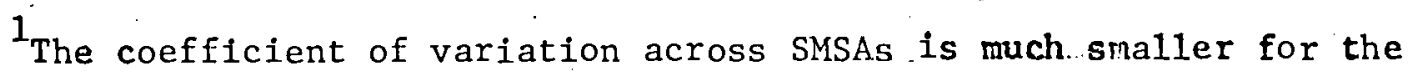
occupancy rate than for the admission rate and bed rate.

(Number of observations $=192)$
1) Occupancy Rate (OR)
$\frac{\text { Coefficient of Variation }}{0.09}$
2) Admission Rate (P)
0.24
3) Bed Rate (Beds*)
0.28
Source: See Appendix A. 
the bed rate is encered as an explanatory variable.

It could be argued that a positive partial correlation between the admission rate and the bed rate is not due to more beds causing more admissions, but rather is due to a higher demand for admissions causing more hospital beds to be constructed. This suggests that the bed rate should be viewed as an endogenous variable (determined within the model) not an exogenous variable (determined outside of the model) in our analysis of hospital utilization.

In the short run the bed rate $\left(B e d s^{*}\right)$ is viewed as fixed, and the hospital admission rate and occupancy rate as interacting simultaneously. In the long run, the bed rate'is not fixed, and the three variables -- p, BEDS* and LnOR-- are interdependent. As the number of beds adjusts to long run conditions, the occupancy rate variable may lose some of its variablity. In the next section a model is developed for predicting the bed rate in an SMSA. The analysis of inter-SMSA differences in admission rates is performed for both a short run model, using predicted LnOR and observed BEDS* as explanatory. variables, and a long run model, using predicted BEDS*. 
(C) Hospital Insurance

It is often argued that the effect of more extensive hospital and surgical insurance coverage is to increase the amount of hospital care and surgery demanded by patients and their physicians. The effect of insurance is a change from a "fee for service" pricing system to an annual lump sum payment independent of the amount of services to be consumed and (usually) a smaller fee for service. By lowering the direct cost to the patient of an additional unit of medical services the patient has an incentive to purchase more medical services than otherwise. This may be done directly by the patient either through requesting more services or by searching for a doctor who will prescribe. these services. The increased use of medical services may also occur if the patient's doctor, seeing the lowered direct price to the patient, suggests or provides more medical care. The adiditional medical care may show up, in part, as a higher rate of hospital admisston. Thus, a greater hospital and surgical insurance coverage is expected to be associated with a higher rate of hospital adruission.

\section{(D) Physicjans}

The number of physicians per capita in an SMSA can be associated with the utilization of their services in several ways. First, the greater the relative number of physicians, holding the demand for their services constant, the lower would be the cost, and consequently the greater the use of their services. ${ }^{1}$ Second, if we hold fixed the supply schedule of physicians

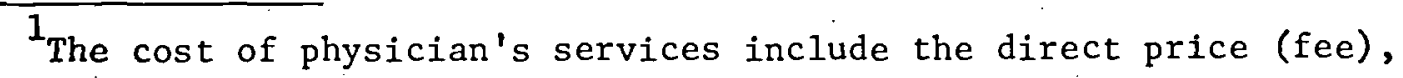
the waiting room time, and the costs incurred due to a delay in receiving care. 
services, communities with a higher demand for health care have a larger number of physicians per capita. (2) Finally, it has been alleged that

(2) This suggests that the number of physicians. is an endogenous variable. However, in this study the observed number of physictans is used in the empirical analysis.

physicians create their own demand: the larger the number of physicians per capita, the greater the amount of medical care received per capita because "consumer ignorance" results in patients placing a great deal of faith in the physician's advice as to the amount end type of medical care that should be purchased and physicians wish to "fill up" their day.

The effect on hospital admissions of an increase in the purchase of

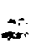
medical care due to the presence of a larger number of physicians depends on whether physicians' services are complementary with or substitutable for hospital services. Surgeons' services are hospital using. It is not clear a priori whether hospital services are substitutes or complements for the medical care provided by non-surgical out-of-hospital physicians. Thus, . ... the number of surgeons per thousand population (SURG*) should have a positive partial effect on admission rates, but the partial effect of non-surgical out-of-hospital physicians per thousand population (GENMD*) is not clear.

It might be asked, "Does the effect of the presence of a larger number of physicians depend on the extent of hospital insurance coverage?" 
This question is answered

by including two linear interaction variables for hospital insurance and physicians per thousand population. ${ }^{1}$

${ }^{1}$ These variables are (a) (HI) (GENMD*) and (b) (HI) (SURG*).

(E) Income

The variable median family income serves several inter-related functions. First, income may be a proxy variable for health status. ${ }^{2}$

2There is evidence that incone and good health are negatively correlated among whites but positively correlated among nowhites. See Michael Grossman, The Demand for Health (NBER, Occasional Paper 119, 1972) and Morris Silver, "An Econometric Analysis of Spatial Variations in Mortality Rates by Age and Sex," V.R. Fuchs, ed., Essays in the Econonics of Health and Medical Care (NBER, 1972) pp. 161-227.

Second, it is not clear a priori whether, ceteris paribus, hospital admissions increase or decrease with income, holding an initial level. of health constant. ${ }^{3}$ Thus, no prediction is offered as to the effect

${ }^{3}$ For a given initial level of health, if preventive or early curative care are less hospital using than cure at later stages, those with higher Incomes may have a lower admission rate. On the other hand, there may be a positive income elasticity of demand for hospital using curative medicine.

of median family income on the demand for admissions across SMSAs. 
F. Climate.

Hospital admission rates appear to be seasonal; they tend to be higher in the fall and winter than in the spring and summer. 1 Thus, if

${ }^{1}$ For example, see Helen Hershfield Avnet, Physician Service Patterns and Illness Rates (Group Health Insurance, Inc. 1967) Table 42, p. 110.

all other variables that influence hospital admissions were held constant, communities with more severe winters would tend to have higher admission rates. Mean January temperature is used as a measure of the severity. of the winter.

\section{(G) The SMSA as a Medical Center}

The dependent variable, the admission rate, is aefined as the number of admissions in the short term general hospitals located in the SMSA in 1967 divided by the population of the SMSA in 1966. An admission rate obtained in this manner is a biased estimate of the hospital admission rate of the population of the SMSA. To obtain the population's admission rate, the admissions of non-residents who used the SMSA's hospitals should be subtracted from the data, while the admissions of residents who entered short term general hospitals outside of the SMSA should be included in the data. Unforturately, it is not possible to make these adjustments.

An alternative procedure is to obtain a proxy for the net in-migration of patients. The net in-migration would be greater, the greater the extent to which the SMSA serves as a health center. An SMSA is more likely to serve as a health center if it has a medical school, and, if a medical school exists, the larger its size. The number of medical school students 
per hundred thousand population is entered for this purpose. ${ }^{1}$

$1_{\text {The variable is defined to be zero for SMSA } s \text { without medical }}$ schools.

\section{(H) Denographic Variables}

The probability of a hospitalization in a year is related to the person's age, sex and race. Thus, admission rates by SMSA will vary witt the age, sex and race composition of the population. Seven variables are included to capture the effects of sex and age differences. ${ }^{2}$ The live birth rate (LBR) is included to control for

2 The seven variables are the percent of the population female (\%FEMAL), and the percents of males and females separately, in the age groups 10 to 39,40 to 54 and 55 years of age and over. 1 :

SMSA differences in fertility. Holding the birth rate constant, the sign of \%FEMAL is expected to be negative as women tend to be more healthy than men of the same age. The percent of the population who are nonwhite. (\%NWHT) is hypothesized to have a positive effect on the admission rate since nonwhites have a lower level of health than whites.

It would be desirable to hold constant a measure of the "healthiness" of the SMSA's environment. The mean January temperature captures some of this effect. Holding constant the median family income and the sex, age, and race distributions of the SMSA, the health status of the environment may be highly correlated with the mortality rate. The number 
of deaths per thousand population (MORT*)

ard is expected to have a positive effect on admissions.

I. Summary:

Combining the separate analyses presented in this section, Table II-2 presents the admission rate equation and indicates the hypothesized effects of each variable. In Chapter III the admissions equation is estimated simultaneously with the occuparcy rate equation and with the bed rate equation. 
Table II-2

Admission Rate Equation $^{\text {a }}$

Dependent Variable: Admissions per Thousand Population (P)

Explanatory Variables:

Name

1) Natural log of occupany rate

2) Bed Rate

3) Hospital and surgical insurance per capita

4) Non-surgical $\mathrm{MD}_{s}$ per thousand population

5) Súrgical $\mathrm{MD}_{s}$ per thousand population

6) Insurance non-surgical MD interaction

7) Insurance surgical $\mathrm{MD}$ interaction

8) Median Fainily Income

9) Mean January temperature

10) Medical Students per hundred thousand population

11) Percent of the population nonwhite

12) Mortality per thousand population

13) Demographic variables

a) Live birth rate

b) Sex

c) Age distribution
Symbol

LnOR

Beds*

HSB /C

GENMD*

SURG*

(HI) (GENMD*)

(HI) (SURG*)

INC

JANTEMP

MST*C

ZNWHT

MORT*

LBR

\%FEM
$+$

?

$+$

$+$

Predicted Effect

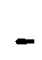

$+$

$?$

$+$

?

-

$+$

$+$

$+$

-

For a detailed definition of the variables and data sources, see Appendix A. 


\section{Bed Rates}

\section{A. Introduction}

Although $\longrightarrow$ the number of hospital beds in an SMSA on January 1 comes prior in time sequence to the number of admissions in that year, this is not a sufficient reason for treating the bed rate as exogenous (deternined outside of the model). The number of hospital beds is a function of past demands and expectations of /demands for these beds, and there is a strong time series correlation in the demand for hospital care. The larger the demand for hospital care, the greater are the economic and political incentives for the government, and religious, other not-for-profit and for-profit organizations to increase the number of hospital beds. This section develops a theoretical model to explain SMSA differences in the bed rate.

\section{B. Admission Rate and the Randomness Model}

If we divide both sides of equation II-15 by the size of the population (in terms of thousands of inhabitants) and $D$, (II-19) Beds* $=\frac{B}{\text { pop }}=\frac{\overline{\mathrm{LS}}(\mathrm{P})}{\mathrm{D}}\left[1+z_{\alpha} \sqrt{\frac{\mathrm{k}}{\text { pop }}\left(\frac{1}{\mathrm{p}}-1\right)}\right]$.

The bed rate indlcated in equation (II-19) is composed of a mean predicted demand $\left[\frac{\overline{L S} \underline{P}}{\mathrm{D}}\right]$ plus a demand due to the stochastic nature of admissions $\left[\left(\frac{\overline{\mathrm{L} G}}{\mathrm{D}}\right)\left(\mathrm{z}_{\alpha}\right) \sqrt{\frac{\mathrm{K}}{\mathrm{pop}}\left(\mathrm{p}-\mathrm{p}^{2}\right)}\right]$. The mean predicted demand in our simplified model is proportional to the admission rate and the length of stay. 


\section{II -25}

The "stochastic demard" is proportional to length of stay, inversely proportional to the square root of the population size, proportional to the square root of the number of hospitals, and positively related to the admission rate (for $p<.5$ ).

We can test the effect of density on the substitutability of hospltal beds. If a greater density increases the substitutability among hospital beds, an SMSA with a smaller land area (holding constant population, admissions and number of hospitals) w111 have

a smaller bed rate.

\section{Hospital Administration}

If beds under different administrative control (government, voluntary, proprietary) were equally. good substitutes for each other, the fraction of beds under a given administration should have no effect on the SMSA's overall bed rate. However, if only veterans can use federal short-term general hospitals, the addition of federal hospital beds has a smaller and indirect effect on bed availability for non-veterans than for veterans. This is expected to increase the number of beds (but by less than the increase in federal beds) and the proportion of beds in federal hospitals: It seems reasonable to assume that state and local government short-term general hospital beds are good substitutes for beds in voluntary huspitals. Although proprietary hospitals charge higher fees than non-profit non-federal hospitals, there are no other special barriers to patient entry. The proportion of proprietary beds in the total bed census is so small, it is unlikely that SMSA variations in proprietary hospital beds have a statistically significant effect on the overaljbed rate. ${ }^{1}$ 
Ftnote from p. 1.25

1/Average across 192 SMSAs of the proportion of beds under each form

of administrative control:

\section{Contro1}

State and Local government

Federal government

Proprietary

Voluntary
Mean

Percent of Beds

15.8

10.6

4.5

$\frac{69.1}{100.0}$

Source: See Appendix A.

Three hospital administration variables are added to the bed rate analysis, the percent of beds in state and local (\%SLBEDS), federal (\%FEDBEDS) and proprietary (\% PRBEDS) hospitals. Insignificant effects are expected for state and local, and proprietary beds. The "veterans effect" is expected to result. in a significant positive effect of federal hospital beds on SMSA bed rates.

\section{D. $\mathrm{Z}_{\alpha}-$ Emergencies and Income}

The parameter $z_{\alpha}$ is the standardized normal variate indicating the proportion of occurrences $(\alpha)$ for which the demand for beds exceeds the available supply. There are no direct measures of $z_{\alpha}$, but we can postulate that it is a function of two variables, the relative importance of emergencies in the SMSA's case mix and median family income.

The more important are emergencies in an SMSA's case mix, the expected of greater is the/cost of delayed (or denied) admissions/because/the demand for beds exceed/ the available supply. Thus, ceteris paribus, the more important are emergencies, the smaller the desired $\alpha$ (larger $\left.z_{\alpha}\right)$, 
and consequently the larger the bed rate. 1

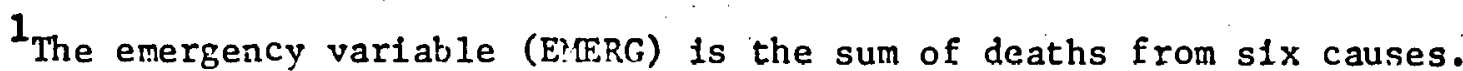
The variable is entered as emergency deaths per thousand population (EMERG*). These six causes are:

(a) Arteriosclerotic heart disease, including coronary conditions (HEART)

(b) Vascular lesions affecting the central nervous system (STROKE)

(c) Motor Vehicle accidents (MOTOR)

(d) Other sccidents (OTHACC)

(e) Suicide (SUIC)

(f) Honicide (HOMIC).

If the availability of a hospital bed is viewed as a superior good, higher income SMSA's would prefer a smaller $\alpha$ (iarger $z_{\alpha}$ ) to reduce the probability that a desired hospital admission would be delayed. This implles a positive effect of income on the bed rate.

\section{E. Percent Nouwhite}

Since nonwhites nave been subjected to discrimination in the provision of other public services, ${ }^{2}$ they may . have been subject to $\overline{2}$ For discrimination in public school: expenditures,see Richard Freeman, "Labor Market Discrimination," paper presented at Econometric Society Meeting, December 1972 or Finis Welch, "Black-White Differences in Returns to Schooling," American Economic Review (forthcoming).

past (and perhaps also current) discrimination in the provision of hospital services. In addition, since non-profit hospitals are financed to a large extent by voluntary contributions from wealthy individuals and foundations, discrimination by these sources against nonwhites implies that SMSAs with a larger fraction of the population nonwhite have a smaller bed rate. To test these hypctheses, a variable for the proportion of noniwhtes in the SMSA's population is added to the bed rate analysis. 
F. Other Variables.

Holding the admission rate and number of hospitals constant, SMSAs which serve as medical education centers are likely to have a larger bed rate. This can be due to both a longer average length of stay and a larger $\mathrm{z}_{\alpha}$ (to reduce the probability of rejecting an "interesting" case) in hospitals affiliated with medical schools.

$\longleftarrow$ The number of medical students per hundred thousand population (MST*C) is used to capture the medical center effect on the bed rate.

- The bed rate in an area is a function of the way its denominator, population, changes. If hospital construction lags behind population growth, the greater the increase in population, the smaller the bed rate. If the community anticipates future demands on the basis of current population growth rates, a positive partial relation would exist between the bed rate and the rate of growth of population (\%CHPOP). In terms of equation (19), holding the admission rate constant, the population growth rate effect would appear as short-run variations in $\ddot{z}_{\alpha}$.

\section{G. Summary}

Table II-3 presents a listing of the variables which enter the bed rate analysis and the hypothesized effects of these variables. The empirical analysis uses a predicted admission rate (rather than the observed admission rate) since the admission rate and the bed rate are simultaneously determined in the long run. 
Table II-3

Bed Rate Equation ${ }^{a}$

Dependent Variable: Beds Per Thousand Population (Beds*)

Explanatury Variables

Name

1) Admission rate

2) Square root of inyerse of population $\left(\sqrt{\frac{1}{\text { pop }}}\right)$

3) Square root of number of hospitals

4) Median family income

5) Emergency deaths per thousand population

6) Medical students per hundred thousand population

7) Area (square miles) per thousand population

8) Percent change in population

9). Percent nonwhite

10) Percent of beds in state and local hospitals

11) Percent of beds in federal hospitals

12) Percent of beds in proprietary hospitals
Symbo1

$\mathbf{P}$

SPOP

$\sqrt{\text { Hosp }}$

INC

EMERG*

MST/C

Area*

\%CHPOP

\%NWHT

\%SLBeds

\%Fed Beds

\%PRBeds
Hypothesized Sign

$+$

$+$

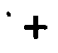

$+$

$+$

$+$

?

$?$

$\because$

0

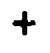

0

a For a detailed definition of the variables and data sources, see Appendix A. 
Chapter III

\section{Empirical Analysis}

Chapter II developed hypotheses and three structural equations to explain regional differences in short tern general hospital occupancy rates, admission rates and bed rates. This chapter presents an empirical estimation of the equations and tests of the hypotheses using the Standard Metropolitan Statistical Area as the unit of observation. 1

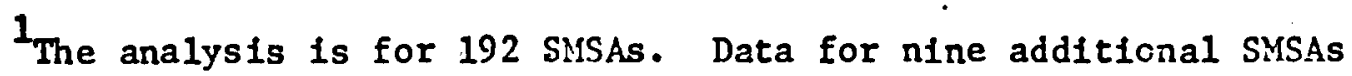
were avallable, but, because of extreme values for the proportion of beds in feleral hospitals and for length of siay, it was felt that long term care or specialty care hospital facilities were included In what was supposed to be short term general hospital data... (See Appendix A.) The two stage least squares regressions for the full sample of 201 SMSAs, as well as the ordinary least squares regressions for both sample sizes, are fresented in Appendix B.

The data for hospital occupancy, admission and bed rates are from a 1967 survey of ail short-term general hospitals in the United States. ${ }^{2}$

\section{Hospitals: A County and Metropolitan Area Data Book, NationaI}

Center for Health Statistics, Department of Health, Education and Welfare, November 1970. For the sources of the data for the explanatory variables, sec Appendix A. 


\section{Occupancy Rate Equation}

\section{a. Randomness Mode1}

If we designate the randomness model variabies by $\left.v=\frac{\sqrt{1}}{\text { pop }}\left(\frac{1}{p}-1\right) k\right)$, we can write equation II-17 as

$$
\text { (III-1). Ln OR }=-\mathrm{z}_{\alpha} \mathrm{V} \text {. }
$$

If the assumptions of the model are valid, the regression of the natural $\log$ of the occupancy rate on the structure of the randomess model (V) will not have an intercept tut will have a negative slope coefficient. Using the normal distribution, the slope coefficient indicates the average proportion of occurrences for which the demand for beds exceeds the available supply $(\alpha)$.

Table III-1 presents the regressions when the admission rate is the annual probabtlity of an admission, divided by 52 , that is, the explanatory variable assumes the time period $D$ is one week. ${ }^{1}$

$1_{\text {Because of the simultaneous determination of the admission rate }}$ and the cccupancy rate, the predicted admission rate is used. The variables used to obtain the predicted adrission rate are the exogenous variables in Tables $B, z-2$ and $B .6,+2$.

When an intercept is allowed, it is insignificant $(t=-1.58)$. Thus, we accept the hypothesis that the intercept is zero. When the regression is forced through the origin, the slope coefficient is highly significant, has a negative sign, and its magnitude indicates that 
TABLE III-1

\section{Randomness Model Analysis of the Occupancy Rate}

Dependent Vartasle: LnOR

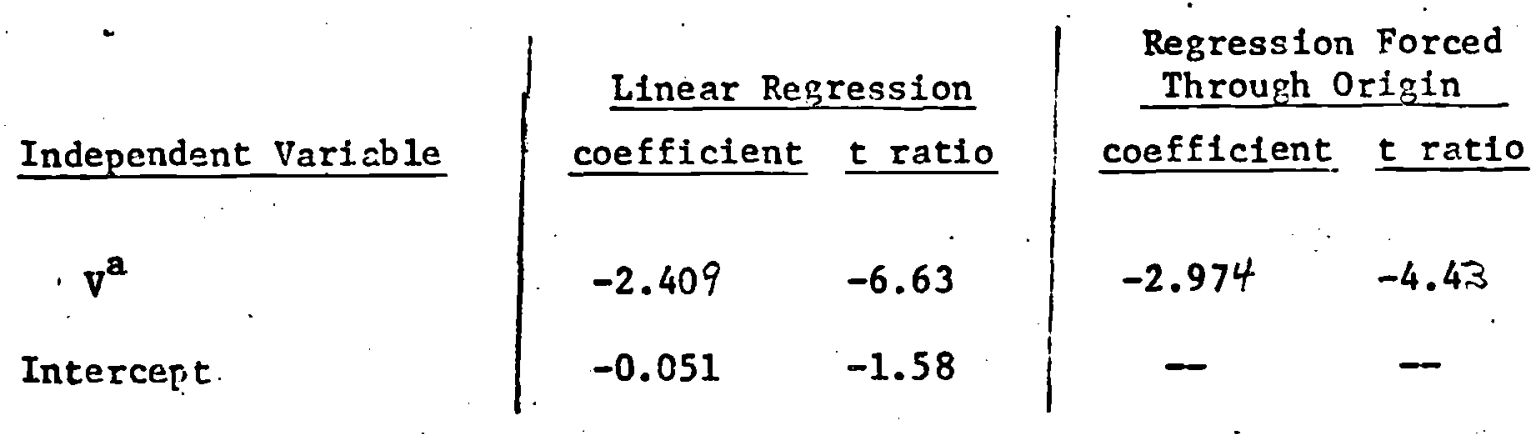

$a_{v}=\sqrt{\frac{1}{p o p}\left(\frac{1}{p}-1\right) k}$, where $p$ is the predicted admission rate per thous and population. (for exogenous variables, see Tables $B-3$, \#2 and $B-6+2)$ divided by $(1,000) \cdot(52)$.

Source: See Append $1 \times$ A. 
the demand for beds exceeds the number available in only 0.15 percent of the weeks $(\alpha=0.0015) .^{1}$ The value of $\alpha$ can be computed for

$1_{\text {For }} Z_{\alpha}=2.973$, using the upper tall of the normal distribution, $a=0.0015=0.15$ percent .

various time periods (D). For example, on approximately 13 percent of the days, some potential patients would be rejected and be subject to either a delayed or a denied admission. 2

${ }^{2}$ For a daily admission rate $\mathrm{p}^{*}=\frac{\mathrm{p}^{\prime}}{7}, \quad$ since $\frac{1}{\mathrm{p}^{\prime}}-1=\frac{1}{\mathrm{p}^{\prime}}$ because $p^{\prime}$ is small, $\operatorname{Ln} O R=\left(\frac{-2.973}{\sqrt{7}}\right) \sqrt{\frac{1}{\text { pop }}\left(\frac{1}{p^{*}}-1\right) k}$, or $z_{\alpha}$ (one day) $=1.12$ and $\alpha$ (one day) $\cong 0.13$.

The findings in Table III-1 provide empirical support. for the randomness model developed in Chapter II. The regression in Table III-?, which uses a looser form of the randomness model variables as well as other control variables, provides additional support for our theoretical analysis of occupancy rates. 3

$3_{\text {The ordinary least squares equation (i.e., the equation using }}$ the observed adnission rate) explains over 40 percent of SMSA variation In the natural log of the occupancy rate.

In Table III-2, the annual admission rate has a positive effect on the occupancy rate. ${ }^{4}$ The mean annual adafssion rate is 170 per 
Table III-2

Two Stage Least Squares Analysis of SMSA Differences in Occupancy Rates Dependent Variaile $=$ LnOR. $N=192$ SiSAs

Variables

ADMS*
BEDS*
SPOP66
SRHOSP
\%NHHT
\%CHGPO
JANTEMP
LBR
\%FEMAL
\%M1039
\%H4054
\%N55
\%F1039
\%F4054
\%F55

const.

\begin{tabular}{cr} 
coefficient & tratio \\
\hline .0015 & 1.94 \\
-.038 & -2.61 \\
-78.556 & -3.54 \\
-.016 & -3.26 \\
.0017 & 2.23 \\
-.00035 & -1.65 \\
-.0028 & -3.91 \\
-.00055 & -1.22 \\
.021 & 0.80 \\
.012 & 0.37 \\
-.014 & -0.37 \\
.016 & 0.51 \\
-.0058 & -0.18 \\
.023 & 0.58 \\
-.011 & -0.36 \\
3.112 & 2.18
\end{tabular}

ADAS* = Predicted Admission Rate - using exogenous variables in this table and Table $B-6$ \#2

Source: See Appendix A. 
${ }^{4}$ The first stage equation used to predict the admission rate has an $\mathrm{R}^{2}$ of approximately 77 percent. Because predicted admissions and the square of predicted admissions are very highly correlated $(R=0.98)$, it was not possible to test for non-linear effects of admissions on the $\log$ of the occupancy rate.

thousand, with a standard deviation of 40.4 per thousand. An increase In the admission rate from 130 per thousand to 210 per thousand (from one standard deviation below to one standard deviation above the mean) predicts an increase in the occupancy rate of approximately 9 percentage points. 1

$$
{ }^{1} \text { Since } \frac{\partial \operatorname{LnOR}}{\partial \mathrm{Adms}^{*}}=+0.0015, \frac{\partial \mathrm{OR}}{\partial \mathrm{Adms}^{*}}=(.77)(+0.0015)=+0.001155 \text {. }
$$

Then, $\quad \triangle O R=+0.001155(210-130)=+0.092$.

The mean occupancy rate is .77 and the standard devfation is 0.067 .

When hospital admissioris are viewed as random events, larger populations have a more stable relative demand for hospital beds and, therefore, are able to maintain a higher occupancy rate. The variable sPop66, the square root of the inverse of the population of the SMSA $\left(\frac{\sqrt{1}}{\text { pop }}\right)$, has a significant effect on the occupancy rate. Going from an SMSA of onequarter of a million to one of one million inhabitants increases the occupancy rate by six percentage points. 2 


$$
\begin{aligned}
& { }^{2} \text { Since } \frac{\partial L n O R}{\partial S P O P 66}=-78.66 \text {, and } \overline{\mathrm{OR}}=.77 \text {, at the mean, } \\
& \begin{aligned}
\frac{\partial 0 R}{\partial \mathrm{SPOP} 66} & =-60.57 . \\
\triangle 0 R & =(-60.57)\left(\frac{1}{4 \Gamma, 000,000}-\frac{1}{\sqrt{250,000}}\right)=-60.57(.001-.002) \\
& =+0.0506 \text { or } 6 \text { percentage points. }
\end{aligned}
\end{aligned}
$$

The difference in occupancy rates between an SMSA with 50,000 inhabitants and one with one-quarter of a million is 15 percentage points.

$$
\left(\Delta \mathrm{OR}_{\mathrm{R}}=-60.57\left(\frac{1}{\sqrt{250,000}}-\frac{1}{\sqrt{50,000}}\right)=-60.57(.002-.00447)=.1^{1 / 9 !}\right)
$$

The randomess mociel also predicts that if beds in different hospitals are not perfect substitutes for ach other, the larger the number of hospitals in an SMSA, the lower the occupancy rate." The model suggests the variable SRHOSP $=\sqrt{\text { number of general hospitals, }}$ which has a significant negative effect on the occupancy rate. Going from four hospitals to sixteen hospitals decreases the bed occupancy rate by 2.5 percentage points. 1

The mean and standard deviation of $\sqrt{\text { Hosp }}$ are 3.2 and 1.92 respectively. Using Table III-2 J. $\quad \frac{\text { aLnOR }}{\text { JVIOSp }}=-0.016$, $\frac{20 R}{\partial V H O S p}=-0.01232$, and $\triangle O R=-0.01232(4-2)=-0.02464$. 
Note that a four fold increase in the number of hospitals and in the population size leaves unchanged the number of hospitals per capita, but the occupancy rate need not be unchanged. An increase in the number of hospitals from 4 to 16 and ar increase in population size from onequarter million to one nillion results in a net increase in occupancy rates. 1 The increase in occupancy rates vith population size when

$$
\begin{aligned}
1_{\mathrm{dLnOR}}= & \frac{\partial \mathrm{LNOR}}{\partial \mathrm{SIOP} 66} \mathrm{dSPOP} 66+\frac{\partial \mathrm{LNOR}}{\partial \mathrm{AHOSP}} \mathrm{d} \text { HOSP } \\
\triangle \mathrm{LnOR} & =(-78.66)(.001-.002)+(-0.016)(4-2) \\
& =(+0.0787)+(-0.032)=+0.0467 \\
\triangle O R & =(.77)(+0.0755)=+0.036
\end{aligned}
$$

hospitals per capita is unchanged suggests

that there is substitution among hospitals but that this substitution is less perfect between than within hospitals. 2

$\tilde{Z}_{\text {That }}$ is, an SiSSA with $k$ hospltals of equal s1ze does not behave as if it were $k$ separate SMSAs each with one $-k$ th of the SMSA's population.

Similar but weaker results emerge when the regression in Table III-2 is computed without the bed rate variable.

$$
\begin{aligned}
& \text { Slope } \quad \text { tratio } \\
& \text { a) SPOP66 }-33.12 \quad-2.54 \\
& \text { b) } \sqrt{\text { Hosp }}-0.011 \quad-2.58 \\
& \text { dLnOR }=\frac{\partial \operatorname{LnOR}}{\partial \operatorname{SPOP} 66} \mathrm{dSPOP} 66+\frac{\partial \operatorname{LnOR}}{\partial \sqrt{\operatorname{liosp}}} \mathrm{d} \sqrt{\mathrm{HOSp}}=0.011
\end{aligned}
$$




\section{b. Other Variables}

The bed rate has a significant negative effect on occupancy rates. A 10 percent increase in the bed rate decreases the occupancy rate by two percent. ${ }^{1}$ This provides only partial support for Roemer's Law

$1_{\text {From Table III-2, }}$

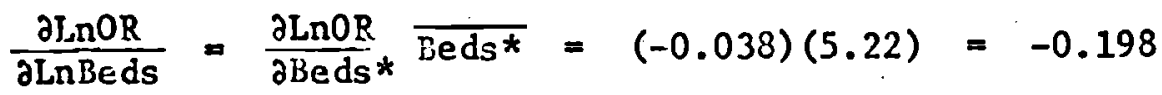

that an increase in the bed rate results in these beds being filled, with no change in the occupancy rate. Since the admission rate is. held constant, and the elasticity of response of OR to Beds* is slgnificantly different from minus unity, length of stay increases w. L th an increase in the bed rate. 2

${ }^{2}$ Since $O R=\frac{(p)(L S)(p o p)}{(365) \text { Beds }}$, and Beds* $=$ Beds $/$ pop,

$\operatorname{LnOR}=\operatorname{Ln}(p)+\operatorname{Ln}(\operatorname{Ls})-\operatorname{Ln}\left(\operatorname{Bed} s^{*}\right)-\operatorname{Ln}(365) \cdot$ Then,

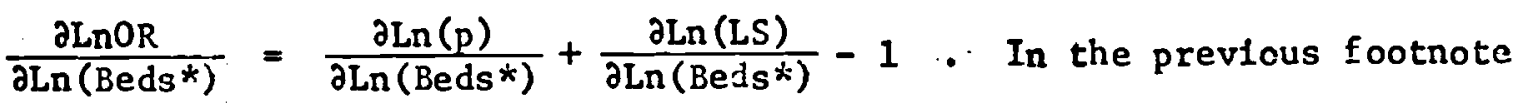
we found $\frac{\partial \operatorname{LnOR}}{\partial \operatorname{Ln}\left(\mathrm{Beds}^{*}\right)}=-0.20$ In the analysis of SMSA differences In admission rates (th1s chapter, part 3), $\frac{\partial \operatorname{Lng}}{\partial \operatorname{Ln}(\text { Beds } *)}=+0.41$. These terms imply that the elasticlty of length of stay with respect to the bed rate is $\frac{\partial \operatorname{Ln}(\operatorname{LS})}{\left.\partial \operatorname{Ln}(\operatorname{Beds})^{\prime}\right)}=+0.39$.

It is hypothesized that there is a negative partial effect of mean January temperature on the mean length of stay and consequently, 
on the occupancy rate. ${ }^{1}$ Empiricaily, mean January temperature has a

$1_{\text {The effect of temperature on occupancy rates through the admis- }}$ sion rate is held constant when we use predicted admissions.

significantly negative effect on occupancy rates. ${ }^{2}$ The variable

2 The average

January temperature is $36^{\circ} \mathrm{F}$,

with a standard deviation of $12^{\circ} \mathrm{F}$. The occupancy rate for SMSAs

one standard deviation above the mean is lower by approximately 5.5

percentage points than the OR for SMSAs one standard deviation below

the mean.

Since, $\frac{\partial \operatorname{LnOR}}{\partial \mathrm{Jantemp}}=-.0028, \frac{\partial 0 R}{\partial J \text { antemp }}=(-.003)(.77)=-0.00231$.

Then, $\triangle \mathrm{OR}=-0.00231(48-24)=-0.05544$.

$\rightarrow$

maintains its slope and standard error even after a South-NonSouth dummy variable or a New England dummy variable is added to the regression equation (see Appendix B).

The proportion of the population of an SMSA who are nonwhite appears to have a significant positive effect on the SMSA's occupancy rate. 3 Going rrom an SMSA with no nonwhites to one with 20 percent

${ }^{3}$ This is not capturing an income effect. When median family income is included in the occupancy rate equation, income is not significant and does not change the effect of percent nonwite (see Appendix B). 
nonwhite (1.e., from approximately one standard deviation below to one standard deviation above the wean) increases the predicted occupancy rate by almost three percentage points. ${ }^{1}$ The positive

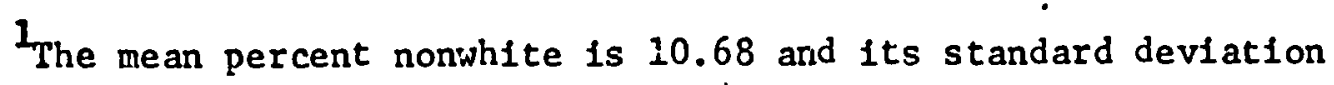
is 10.5 percent. Using Table III-2, $\quad \frac{\partial L n O R}{\partial \% N H T H}=0.00173$. $\frac{\partial O R}{\partial \% \mathrm{NWHT}}=(0.00173)(.77)=0.00133$ and $\Delta O \mathrm{R}=(0.00133)(20.0-0.0)=0.0266$.

effect of percent nonwhite, when the adnission rate and bed rate are held constant, suggests there is a longer average length of stay for nonwhites. 2

There is other evidence of a longer nonwalce length of stay. For example, the average length of hospital stay in New York City in 1964 was

$\begin{array}{llc} & \text { Male } & \text { Female (excluding deliveries) } \\ \text { White } & 13.8 & 10.5 \\ \text { Nonwhite } & 16.0 & 16.4 \\ \text { Puerto Rican } & 19.9 & 14.4\end{array}$

Source: Hospital Discharges and Length of Stay, New York C1ty, 1964 (New York City, Population Health Survey, Septemoer 1966, Report Number $\mathrm{H}-1$ ), Table 8.

The variable "percent change in population" has a negative effect (significant at the 10 percent level) suggesting that more rapidly growing SMSAs have $\stackrel{\text { shorter }}{A}$. lengths of stay, either because of a healthier population or environment. Eight other variables are 
added to the occupancy rate equation to control for SMSA differences In length of stay due to differences in the live birth rate (LBR), the sex distribution (\%FMAI = percent of the population female), and the age distribution. These demographic variables are generally not separately significant.

\section{c. Summary}

The empirical analysis of SiSA differences in occupancy rates permits a test of the hypotheses developed in Chapter II, Part 2. The findings confirm the predictions of the randomness model. There is a positive efrect of the admission rate on the occupancy rate: SMSAs with higher admission rates have higher occupancy rates, More populous SMSAs are able to take advantage of the effect of population. size and maintain a higher oscupancy rate. A larger number of hospitals decreases the occupancy rate, presumably because of a poorer referral system between than within hospitals. Communication does occur across hospitals, as shown by the higher occupancy rate when population size and number of hospitals are increased proportionately.

Hoiding the admission rate constant, a higher bed rate implies a lower occupancy rate (the eiasticity is -0.2 ). Thus, an increase In beds is associated with both an increase in length of stay (elasticity is t0.39) and a decrease in the occupancy rate. This is only partial support for Roemer's law that when more beds are avallabie they tend to be f11led.

Longer lengths of stav explain the findings that occupancy rates are higher in SMSAs in colder winter climates and with a larger fraction of the population nonwhite. 
The empirical analysis

Indicates that occupancy rates vary across SMSAs and that this

variation can be related systematically to the characteristics of the SMSA. 
2. Admission Rate Equation

\section{a. Introduction:}

The second dependent variable examined theoretically in Chapter II is the hospital admission rate. The admission rate is defined as the total number of admissions in a year in the SMSA's short term general hospitals divided by the population in thousands of the SMSA. The mean and standard deviation of the admission rate are 170 and 40 , respectively, and the range is from 60 to 290.1 !

\section{$\underline{1}$ The data are for 192 sasAs. See Appendix A.}

The regression equation developed in Chapter II for explaining SMSA differences in the hospital admission rate is estimated simultaneously with the occupancy rate in our "short run" model (Table III-Z), and simultaneously with the bed rate in our "long run" model (Table III-4) 2 .

of Inter-SMSA variation in the admission rate in the ordinary least squares regression analysis (See Appendix B).

\section{b. Endogenous Explanatory Varlable: Occupancy Rate}

The cost to the hospital or society of a patient occupying a bed depends, in part, on the space (beds) available. The more crowded are 


\section{III -13}

hospitals (higher bed occupancy rate), for a fixed number of beds, the more likely it is that accepting an admission precludes (or delays) accepting another patient with a more "urgent" demand for hospital care.

As expected, the predicted natural. $\log$ of the occupancy rate has a significant negative effect on the admission rate. A one percentage point increase in occupancy rates, ceteris paribus, decreases the admission rate by over four admissions per thousand population per year. $\underline{1}^{\prime}$

1/ In Table III-3, regression 2, at the mean $O R$,

$$
\begin{aligned}
& \frac{\partial A d m s^{*}}{\partial \operatorname{LnOR}}=\frac{\partial \text { Adms }^{*}}{\partial \mathrm{OR}} \overline{\mathrm{OR}}=-341.9 \\
& \frac{\partial \mathrm{Adms}^{*}}{\mathrm{OOR}}=\frac{-341.9}{\overline{\mathrm{OR}}}=\frac{-341.9}{.77}=-444.0 .
\end{aligned}
$$

Thus, a one percentage point increase in the occupancy rate $(\Delta O R=0.01)$, In the neighborhood of the mean $O R$, results in a decrease in admissions per thousand population by 4.44 .

Holding the predicted occupancy rate constant, a larger bed rate (Beds*) implies a larger absolute number of vacant beds per capita. A larger absolute number of vacant beds per capita implies a lower probability that an admission will preclude or delay the admission of a patient with a more serious illness. The variable Beds* does indeed have the expected significant positive partial effect on the admission rate (Table III-3). An increase of one bed per thousand population is associated with an 11.2 per thousand population increase in the admisston rate. 2 /

2/ The mean and standard deviation of bed rate are 5.22 and 1.44 , respectively. A one bed per thousand increase represents nearly a 20 percent increase in the stock of beds. 
Table III-3

Two Stafe Least Squares

Analysis of SMSA Differences in Hospital Adrission Rates

Dependent Variable $=$ ADMS $*$

$\mathrm{N}=192$ SNISAS

\begin{tabular}{|c|c|c|c|c|c|}
\hline & 1. $\mathrm{W} / \mathrm{LnOH}$ & $B-3, \quad \equiv 1)$ & 2. $\mathrm{W} / \mathrm{LnO}$ & $R(T a$ & $B-3, \quad$ 非 2$)$ \\
\hline Variables & coef. & t ratio & coef. & & $t$ ratio \\
\hline LñR & -362.350 & -3.27 & -341.875 & & -3.23 \\
\hline BEDS* & 10.627 & 3.60 & 11.191 & & 4.05 \\
\hline $\mathrm{HSB} / \mathrm{C}$ & 2.296 & 2.03 & 2.999 & & 2.98 \\
\hline GENMD: & -101.480 & -0.80 & & & \\
\hline SURG* & 545.074 & 2.73 & 469.103 & & 3.17 \\
\hline $\mathrm{HI} * \mathrm{XMD} *$ & 2.343 & 0.96 & & & \\
\hline HI $* X S G^{*}$ & -9.437 & -2.43 & -7.615 & & -2.71 \\
\hline INC & -19.901 & -3.28 & -22.896 & & -4.36 \\
\hline JANTERP & -1.961 & -3.80 & -1.839 & & -3.65 \\
\hline \%TRADE & 1.068 & 0.75 & $\ddots$ & & \\
\hline$\%$ NWHT & 1.053 & 2.48 & .938 & & 2.23 \\
\hline LEN & -.248 & -1.15 & . & & : \\
\hline \% FELAAL & -24.682 & -2.32 & -22.219 & & -2.22 \\
\hline NORT* & -4.702 & -1.11 & -4.346 & & -1.04 \\
\hline \%MO39 & -37.894 & -3.27 & -33.188 & ... & -3.08 \\
\hline$\%$ N4054 & -54.915 & $-3: 65$ & -48.251 & & -3.43 \\
\hline$\%$ M55 & -34.035 & -2.77 & -29.365 & & -2.56 \\
\hline \%F1039 & 38.133 & 3.24 & 33.517 & & 3.01 \\
\hline$\% \Gamma 4054$ & 58.752 & 3.64 & 52.413 & & 3.40 \\
\hline$\%$ F55 & 33.668 & 2.80 & 29.029 & & 2.58 \\
\hline NEiNGL & -15.864 & -1.23 & -16.329 & & -1.33 \\
\hline MST $* C$ & $\therefore .061$ & -0.65 & & & \\
\hline const & 2899.88 & 3.60 & 2653.57 & & 3.82 \\
\hline
\end{tabular}

LnOR = Predicted Log Occupancy Rate - - using exogenous variables in this table and in Table B-3, \#1 and $\# 2$.

Source: See Appendix A. 
The net cost to the patient of a particular hospitalization is lower, the greater the extent that insurance pays for hospital and surgical expenses. The insurance variable used in this study is an estimated value of the benefits from hospital and surgical insurance per capita in the SMSA. I/ It is expected to have a positive effect on the

$1 /$ The estimation procedure is discussed in Appendix A.

admission rate. $\underline{2}$

2/ In principle, the causation could run in the opposite direction. That 1s, SMSAs with larger hospital admission rates for some reason other than Insurance might have an incentive to buy more dollars worth of insurance. This effect is not likely to be important in this study as the hospital insurance variable is ccmputed from an interstate regression of state values for hospital insurance on several explanatory variables which are exogenous to the model of the hospital sector developed in this study. See Appendix A.

Variables are included to test the effect of the presence of physicians per thous and population. Non-surgical M.D.s (GENMD*) and surgical M.J.s per thousand population (SURG*) are entered separately. It is argued in Chapter II that it is not clear a priori whether more nonsurgical M.D.s per thousand population increases the use of hospitals (since the cost of medical care is cheaper and more of all medical care is purchased) or decreases the use of hospitals (since hospital care and out-of-hospital nonsurgical M.D. 
care may be alternative means of improving one's health). Since the care provided by medical doctors specializing in surgery is hospital-using, a larger SURG* is expected to be associated with a greater admission rate. Surgical and non-surgical hospital treatment are less expensive to the patient, the greater the extent of insurance coverage.

Insurance $(H S B / C$ ) and surgeons (SURG*) have significant positive effects and the insurance-surgeon interaction variable has a significant negative effect on the admission rate. The number of non-surgical N.D.s has no effect on hospital admissions. The significant negative slope for the insurance-surgeon interaction variable says that the effect on the admission rate of an extra surgeon per thousand population is smaller the greater the amount of insurance. That is, the more insurance benefits the SMSA receives, the greater the amount of hospitalization; but this incremental effect is smaller, the larger the number of surgeons per capita. This negative effect is contrary to our expectations. The effect on admissions of the number of surgeons is positive at the mean level of insurance. $1 /$

$\underline{1}$ For Table III-3, regression 2 , since $\overline{\mathrm{HSB} / \mathrm{C}}=50.5$,

$$
\frac{\text { aAdms: }}{\text { aSurg* }}=469.1+(-7.615)(\overline{\mathrm{HSB} / \mathrm{C}})=84.5
$$


Median family income in the SMSA has a negative effect on hospital admissions. This may be due to the higher value of time for families with grester income and the substitution of.less time consuming out-of-hospital care for in-hospital treatment. It may also reflect a greater efficiency in producing health outside of the hospital on the part of those with more schooling. 1 /

$1 /$ The average median family income is $\$ 5,808$, and the standard deviation is $\$ 838$. The equation says that going from an SMSA with a $\$ 5,000$ median family income to one with a $\$ 6,600$ income decreases admission rates by 37 per thousand per year. (Inc is in thousands of dollars.) The elasticity of admissions with respect to income at the mean is -0.78 . Source: Table III- 3 , regression 2 .

The proportion of the population of the SMSA who are nonwhite has a significant positive effect on the rate of admission to short-term general hospitals. $2 /$ The effect occurs after controlling for median family income,

2f $\frac{\partial \text { Adms* }}{\partial \% N W T}=0.938$. The maan and standard deviation of percent nonwhite are 10.68 and 10.5 , respectively. A ten percentage point increase in the proportion nonwhite increases the admission rate by 9 per thousand population.

among other variables.)

There are two possible interpretations of the nonwhite effect.

First, since nonwhites are on the average poorer than whites, for two

SMSAs to have the same median income, the one with the larger percent nonwhite has a lower mean and a larger variance of income. A simple 
non-linear Engel curve for hospital admissions could generate a negative partial effect on admissions for the variable percent nonwhite. I/ second, ceteris paribus, nonwhites have higher hospital

$1 /$ For the $i^{\text {th }}$ family let

$$
A d m_{i}=a+a_{1} I_{i}+a_{2} I_{i}^{2}
$$

where $a_{0}>0, a_{1}>0, a_{2}<0$.

Computing the mean of both sides of the equation,

$$
\overline{\mathrm{Adm}}=a_{0}+a_{1} \overline{\mathrm{I}}+\mathrm{a}_{2}\left(\overline{\mathrm{I}}^{2}+\operatorname{Var}(\mathrm{I})\right) \text {, }
$$

where $\operatorname{Var}(I)$ is the variance of family income. A larger income reduces admissions if $\frac{\overline{\partial A d m}}{\partial \bar{I}}=a_{1}+2 a_{2} I<0$ or if $-a_{1}>\Sigma_{2} a_{2} \bar{I}$. The empirical

analysis did find that larger median incomes reduced admission iates, and mean and median incomes are highly correlated across areas. A larger variance of income (mean constant) reduces admissions as long as $a_{2}<0$.

admission rates than whites.

Tt SMSAs with colder winter temperatures have higher hospital admission rates. 2 /

2/ This effect is not due to regional differences. Dummy variables for South and New England were statistically insignificant and do not alter the climate effect.

- Attempts to find a medical center effect on admissions were unsuccessful. In Table III-3, regression 1 , the number of medical students per hundred thousand population is insignificant. Other attempts using variables for medical schools" 
and the extent to which the SMSA is a center for trade and commerce were also unsuccessful.

c. Endogenous Explanatory Variable: The Bed Rate.

While it may be appropriate for a short-run model to view the bed rate as exogenous, this is clearly not correct for a long-run model. Economic theory predicts that in the long run the bed rate is a positive function of the admission rate. l'sing the observed bed rate rather than the predicted bed rate biases the effect of beds on the admission rate. Table III- 4 presents the estimated admission rate equation for the long-run model using the predicted bed rate and without the occupancy rate variable. - The predicted bed rate has a significant positive effect on the admission rate. A one bed per thousand increase in the bed rate

1/ The interpretation of the statistical significance and direction of effects of the other (exogenous) variables is the same as in Table III-3, except that percent nonwhite becomes statistically insignificant.

$\leftarrow$ increases the admission rate by 13.2 per thousand.

This implies a long-run response elasticity of admissions to beds of

0.41 .21 This elasticity is larger than the response of admissions to beds

$2 /$ The elasticity of admissions with respect to predicted beds is

$$
\varepsilon p, b=\frac{\% \Delta \text { Adms }}{\% \Delta \text { Beds }}=\frac{\Delta \text { Adms }}{\Delta \text { Beds }} \frac{\overline{\text { Beds }}}{\text { Adms }}=(13.17)\left(\frac{5 . ?}{17 \%}\right)=0.41 .
$$


Table III-4

Two Stage Least Squares

Analysis of SMSA Differences in lospiral Admission Rates

Dependent Variable $=$ NDMS $*$

$\mathrm{N}=192$ SMSAS

Variables

$\hat{\imath}$

BEDS*

$\mathrm{HSB} / \mathrm{C}$

SURG*

$\mathrm{HI} * \mathrm{XS} \mathrm{G}^{*}$

INC

JANIENP

MST ${ }^{*} \mathrm{C}$

\%NWLT

LBR

\%FEMAL

\%1039

$\% 4054$

\%M55

\%F1039

$\% \mathrm{~F} 4054$

$\%$ F55

const. coefficient

13.176

- 1.290

261.804

$-3.189$

$-18.419$

$-.659$

$-.117$

.136

$-.044$

$-21.363$

$-25.924$

$-31.978$

$-23.291$

24.003

28.831

20.741

.1372 .16 $t$ ratio

5.30

2.04

2. 79

$-1.79$

$-4.53$

$-2.66$

$-1.75$

0.56

$-0.29$

$-2.79$

$-3.28$

$-3.48$

$-2.73$

3.07

3.00

2.52

3.10

Bêds* = Predicted Bed Rate -- using exogenous variables in this table and in Table $B-9$, $\$ 2$.

Source: See Appendix A. 
In the short-run model where the bed rate is viewed as an exogenous variable. $1 /$

1/ The elasticity of admissions with respect to obseryed beds is

$$
\varepsilon \mathrm{p}, \mathrm{b}=-\frac{\% \Delta \mathrm{Adms}}{\% \Delta \operatorname{Bed} s}=(11.2)\left(\frac{5.2}{170}\right)=0.34 .
$$

Source: Table III- $\$$, regression 2 .

Thus, there is a "beds effect" -- more beds, ceteris paribus, mean more patients (admissions) will occupy the beds. Since the elasticity is less than unity, the occupancy rate decreases, or the length of stay increases in response to an increase in the bed rate not die to an increase in admissions.

-d. Sumnary

The empiricai estination of the adinission rate ecqution indicates a significant negative effect of the (predicted) occupancy rate on the admission rate. A one percentage point increase in the occupancy rate decreases the adinssion rate by 4.4 per thous and population. There is also a positive effect of the bed rate on the admission rate. A (shorit recumodel) $A$ one bed per thousand increase in the observed stock of beds increases admissions by 11.2 per thousand; the elasticity at the mean is +0.34 . When the bed rate is treated as an endogenous variable (the long run mode1), the elasticity is t0.4.1.

The "hospital and surgical insurance" variable and the number of surgeons per capita have positive effects on the admission rate. However, there appears to be no relation betwenn the number of 
non-surgical. MDs and the admission rate.

Median family income is negatively correlated with adnissions, with an elasticity of -0.78 . SMSAs with a higher proportion of the population nonwite and with colder winter climates have higher hospital admission rates. The attempt to identify a medical center effect on the admission rate was not successful.

The empirical analysis Indicates that hospital variables (occupancy rate, bed rate), hospital insurance, surgeons per capita, income, climate and demographic variables all play a role in determining a Standard Yetropolitan Statistical Area's admission rate for short tert general hosititals.

3. Bed Rate Equation

This section presents the empirical analysis of SMSA differences

- in the number of short-term general hospital beds per thousand population. 1 /

\section{(1)}

The explanatory power of the ordinary least. squares erquation is 76 percent. The regression in Table III- 6 containfonly the variables with t-ratios greater than 1.0 in Table III- 5 .

Although the number of beds in an SMSA can be viewed as being fixed in the short run, this is not an appropriate assumption for a long-run analysis. The admission rate and the bed rate equations are estimated simultaneously because of their interdependence: a higher demand for admissions increases the supply of beds, and a greater supply of beds increases the number of 
admissions. The mean and standard deviation of the bed rate are 5.2 and 1.4 respectively, and the range is from 2.0 to 9.2 .2 I

2/ The data are for 192 SMSAs. See Appendix A.

The predicted admission rate has a strong positive effect on the observed bed rate. (Table III-5). The elasticity of the bed rate with respect to the predicted admission rate is $0.92 \frac{3}{}$ / Thus, a one percent increase

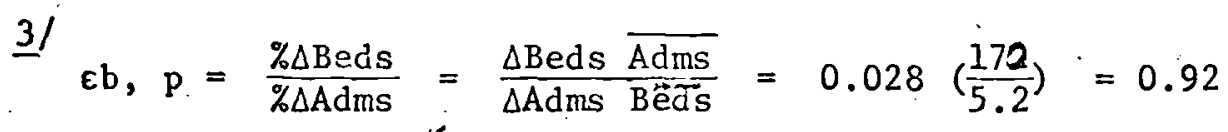

in the admission rate due to forces exogenous to the model increases the prelccter!
prict bed rate by nine-tenths of a percent. The effect of the $\Lambda^{\text {admission rate on }}$ 
Table III-5

Two Stage Least Squares

Analysis of SMSA Differences in Hospital Béd Rates

Dependent Variable $=$ BEDS:

$\mathrm{N}=192$ SNSAs

Variabies

AÔMS

INC

$\mathrm{MST} * \mathrm{C}$

\%NWHT

SPOPG6

SRHOSP

$\%$ CHGPO

EMEKG*

\%SLBED

\%FDEED

\%PRBED

AREA $: C$

const. coefficient

.028

.106

. .0045

$-.0065$

$-162.704$

$-.011$

$-.00068$

.347

.00023

.045

.0026

$-.000012$

$-1.641$

\section{tratio}

9.63

1.32

2.30

$-1.05$

$-0.99$

$-0.23$

$-0.35$

5.16

0.07

10.25

0.38

$-0.15$

$-2.02$

ADPS: ${ }^{*}$ Predicted Admission Rate -- using exogenous variables in this table and in TAble $\mathrm{B}-8, \# 2$.

Source: See Appendix A. 
$7 \pi-216$

Table III-6

Two Stage Least Squares

Analysis of SMSA Dififerences in Hospital Bed Rates

Dependent Var1able $=$ BEDS*

$\mathrm{N}=192$ SMSAs

Variables

$\lambda$

ADMS

NST *C

FMERG*

\%FDBED

INC

\%NVHT

const. coefficient

.025

.0055

.372

.047

.137

$-.0044$

$-1.961$ $t$ ratio

10.44

3.15

6.20

11.90

1.76

$-0.76$

$-2.36$

$\hat{A D M S}=$ Predicted Admission Rate -- using exogenous variables In this table and in Table $\mathrm{B}-8$, \#2.

Source: See Appendix A. 
the bed rate is, therefore, considerably stronger than the effect of the bed rate on the admission rate. 1 /

$1 /$ Recall from Part 2 of this chapter that the elasticity of admissions with respect to beds was 0.41 in the long run mode1.

The model of the randomness of demand for hospital admissions predicts positive partial effects on the bed rate of our measure of population size, $\sqrt{\frac{1}{\text { pop }}}$, and our measure of the number of hospitals, $\sqrt{\text { Hosp. }}$. In spite of the significance of these variables for explaining SMSA differences in occupancy rates, they play no role in determinitig the bed rate.

The randomness model of admissions also hypothesizes that the number of beds in a comnunity is a function of the probability that patients will have to be granted a delayed or denied admission. The greater the cost of a delayed'admission, the greater the demand for beds, ceteris paribus. $\longleftarrow$ The cost of a delayed admission is greater, the more important are emergencies in the SMSA's hea1th picture. An emergency variable (Emerg*), measured as the death rate from '.. "emergency" causes per thousand population, is included in the bed rate equation. $2 /$ It has a significant positive effect

They - are arteriosclerotic heart disease, strokes, motor vehicle and other accidents, suicides and homicides.

on the bed rate.

In the full equation for the bed rate, median family income has an insignificant positive effect (Table III-5). When variables with t-ratios 
less than unity are deleted, income has a significant positive slope (Table III- b.) and an elasticity of +0.12 / This may reflect a positive

2/ $\frac{\% \Delta \text { Beds* }}{\% \Delta \text { INC }}=\frac{\Delta \text { geds* }}{\Delta \text { INC }} \frac{\overline{\text { Beds* }}}{\text { INC }}=(0.137)\left(\frac{5.2}{5.81}\right)=+0.12$.

income elasticity of demand for "excess capacity" to reduce the probability that a desired admission will be delayed.

$2 /$ The mean and standard deviation of income are $\$ 5,808$ and $\$ 833$, respectively: Going from an SMSA one standard deviation below the mean to an SMSA one standard deviation above the mean implies an increase of two-tenths of a bed per thousand population, or 223 beds in an SMSA vith a population of one mill1on.

$$
\Delta \text { Beds }^{*}=0.137 \Delta \mathrm{INC}=0.137(1.63)=0.223
$$

INC is in thousands of dollars.

To test the hypothesis that SMSAs which serve as medical centers have larger bed rates the analysis includes the variable the number of medical students per hundred thousand population (MST*C). It has a significant positive effect. The slope coefficient implies that the addition of a 400 student medical school (100 students per year) to an SMSA with one-million inhabitants increases the number of beds per thousand population by twotenths of a bed. or the number of beds by $220 .{ }^{3}$ $\underline{3 /} \Delta$ Beds* $=.0055(\Delta / S T * C)=.0055(40)=.22$. 
The three explanatory variables for administrative control

(the proportion of beds in federal, state and local, and proprietary hospitals) would have insignificant effects on the bed rate if beds In these hospitals were perfect substitutes for beds in voluntary hospitals. Explicit barriers to admission or imperfect referral systems would result in positive effects. The effects are insignificant for state and local and proprietary hospitals, but positive and highly significant for federal hospitals. This presumably reflects the required veteran status for entry into federal hospitals. ${ }^{1}$ A one percentage point increase in

1/ Note that this positive partial effect of the proportion of beds in federal hospitals on the bed rate cannot be explained by federal hospitals attractirg admissions from outside the SMSA. The effect of federal hospitals. on admissions appears in the predicted admissions variable in the bed rate equation.

the proportion of beds in federal hospitals increases the bed rate by +0.047 . However, if there were no response of non-federal beds to an increase in federal beds, at the mean, a one percentage point increase in federal beds would increase the bed rate by $+0.055 .^{2}$ An increase in

2 The mean bed rate is 5.22 and the mean percent of beds in federal hospitals is 10.64 percent. (Source: Appendix A.)

federal beds is associated with an increase in the overall bed rate, and a decrease in the non-federal bed rate. ${ }^{3}$. 


\section{(fcotnote 3 from previous page $(I I I-24))$.:}

\section{${ }^{3}$ Since $\overline{\text { Beds }^{*}}=5.22$ and $\overline{\% \text { FDBEDS }}=10.64, \overline{\text { FedBeds* }}=0.55$, and}

$\overline{\text { NonFedBeds } \bar{x}}=4.664$. A one percentage point increase in federal beds Implies an increase in FedBeds* by 0.067 , if the number of non-federal beds is constant. However, a one percentage point increase in the percent of federal beds increases the bed rate by 0.047 . Since $\Delta$ Beds $*=\Delta$ NonFedBeds $*+\Delta$ FDBeds $*, \Delta$ NonFedBeds $*=-0.20$. For an SMSA with a population of one million, an additicnal 134 bed federal hospital decreases the number of non-federal bcds by 40 , for a net increase of only 94 beds.

Thus, we reject the hypothesis that a bed in a federal hospital is a perfect substitute for a bed In a non-federal hospital.

The proportion of nonwhites in the population has no effect on the bed rate. Recall, however, tilat SMSAs with more nonwhites have higher admission rates and occupancy rates. The higher occupancy rate in SMSAs with more nonwhites (holding the admission rate and bed rate constant) appears to be due to a longer length of stay of ncnwhites. The two remaining variables, the rate of growth of the population and the area of the SMSA, appear to play no role in explaining SMSA differences in the bed rate. 
The empirical analysis indicates that the bed rate varies systenlatically across SMSAs. The (predicted) hospital admission rate, the importance of emergencies in the SMSA's case.mix and the proportion of beds in federal hospitals are the most important variables and have positive effects on the bed rate. SMSAs which are wealthier or serve as medical centers tend to have larger bed rates, but these variables are of lesser overall importance. 
Table A-1, The Variables, presents a listing of the variables used in this study, theix symbols, and a code for the source of the data. Table A-2, Sources, has the detailed bibliographic information on the sources. Table A-1 also presents the mean, standard deviation and coefficient of variation for each of the variables for the sampie of 192 Standard Metropolitan Statistical Areas.

The empirical analysis is performed for the samples of 192 and 201 SMSAs. Although the data exist for all 201 SMSAs, nine are excluded to form the smaller sampie because of either an excessively laxge fraction of beds in federal hosfitals or very long computed lengths of stay. l. Either variable suggests the presence of long term care facilities in the data.

\section{1}

(A) Nine SMSAS

Ann Arbor, Michigan

Augusta, Georgia

Durham, North Carolina

Galveston, Texas

Little Rock, Mrkansas

Providence, Rhode Island

Sioux Falls, South Dakota Tacoma, Washington

Topeka, Kansas
Percent of Beds

in Federal Hospitals
Average Length

of Stay

-(B) 192 Si1SAs

Mean

2.1 .78

12.4

76.13

22.4

31.96

8.71

11.6

60.59

7.30

36.70

0.0

13.6

18.8

18.0

10.0

60.96

23.6

22.0

Standard Deviation

10.64

13.45
8.8

1.9 
Data on hospital and surgical insurancè coverage per capita or per household do not exist on an SMSA basis. State data are used to predict the SMSA insurance variable. The insurance variable is "total hospital and surgical insurance benefits" in the state divided by the population of the state $(H S B / C)$. States without SMSAs and across which there is considerable commutation are excluded from the state regression. This leaves a sample of 41 states. The equation used to predict SHSA values for $\mathrm{HSB} / \mathrm{C}$ is an inter-state weighted regression (see Table A-3) $\ldots$ and is the "best" equation obtained after experimenting with the data. The explanatory variables are the percent of the state's labor force employed. (a) by local governments, (b) by the federai government, (c) in manufacturing and (d) in white collar jobs. The coefficient of cetermination adjusted for degrees of freedom is seventy percent. 
Coefficient of

Variation

A) Endogenous Variables

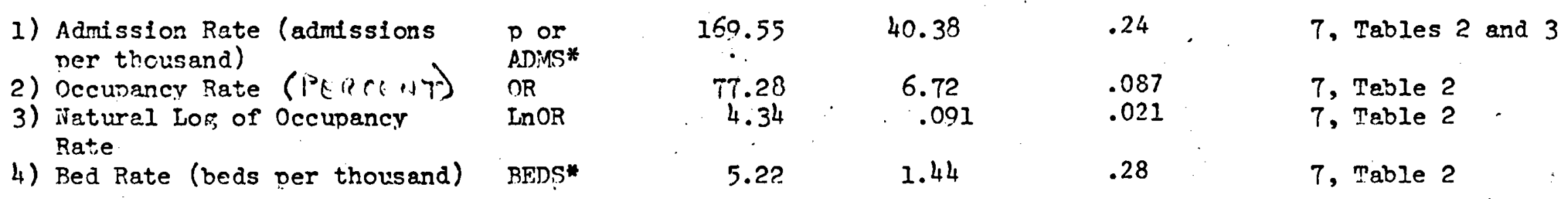

B) Exogenous Variables

I) Population of SMSA, 1966 (thousands)

2) \% Change in Population, $1950-1960$

3) \% Non-white

4) Median Family Income (thousand \$)

5) \% or Gener2]. Hospital Beds which are in State and Local Government Hospitals, 1967

6) \% of Genira? Hospital Beds which are in Federal Hospitals, 1967

7) \% of Generai Hosoital Beds which are in Proprietary Hospitels, 1967

8) South/Non-South dummv, South $=1$

9) I:and Arca of SMSA (in square miles)

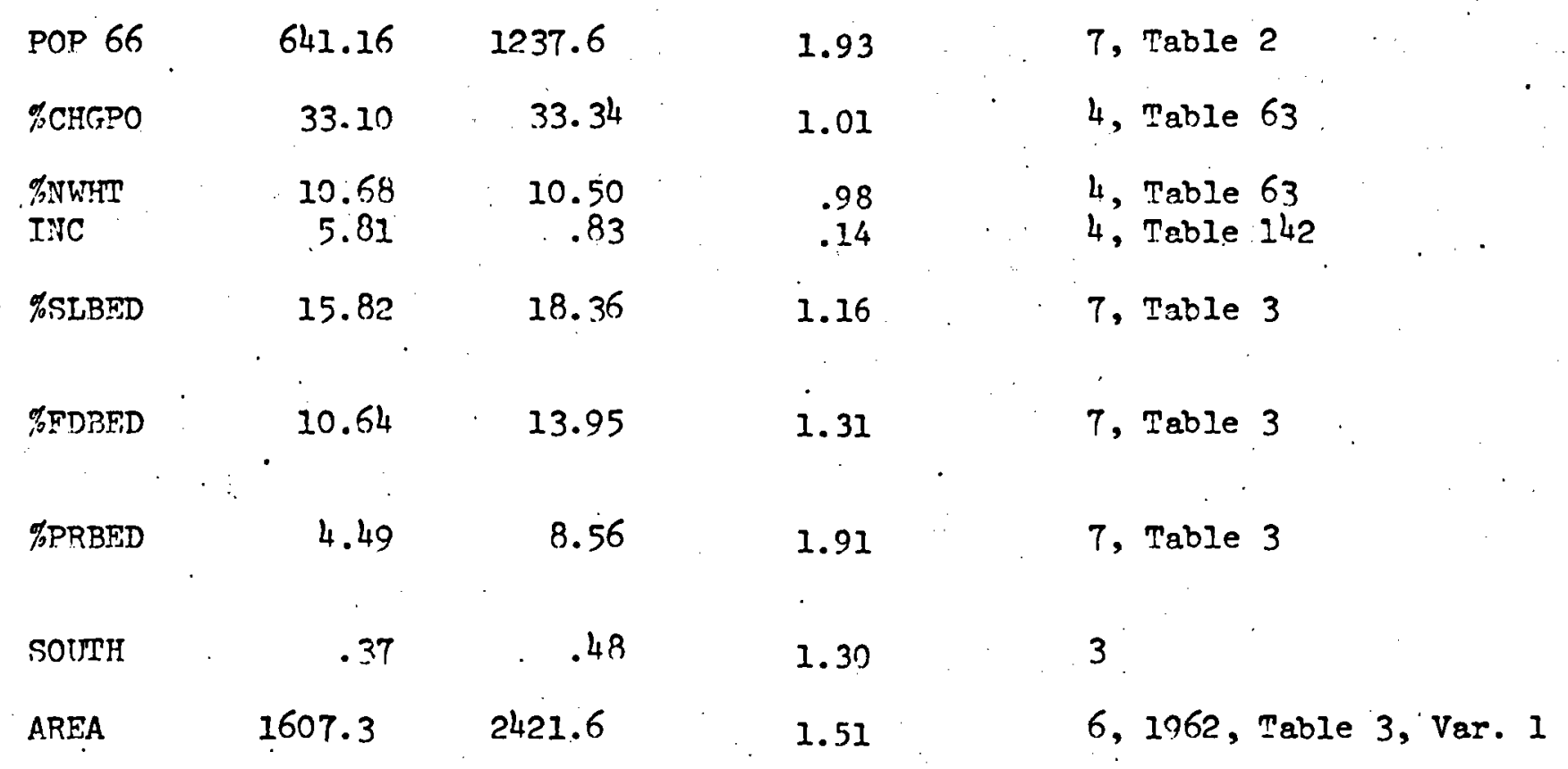




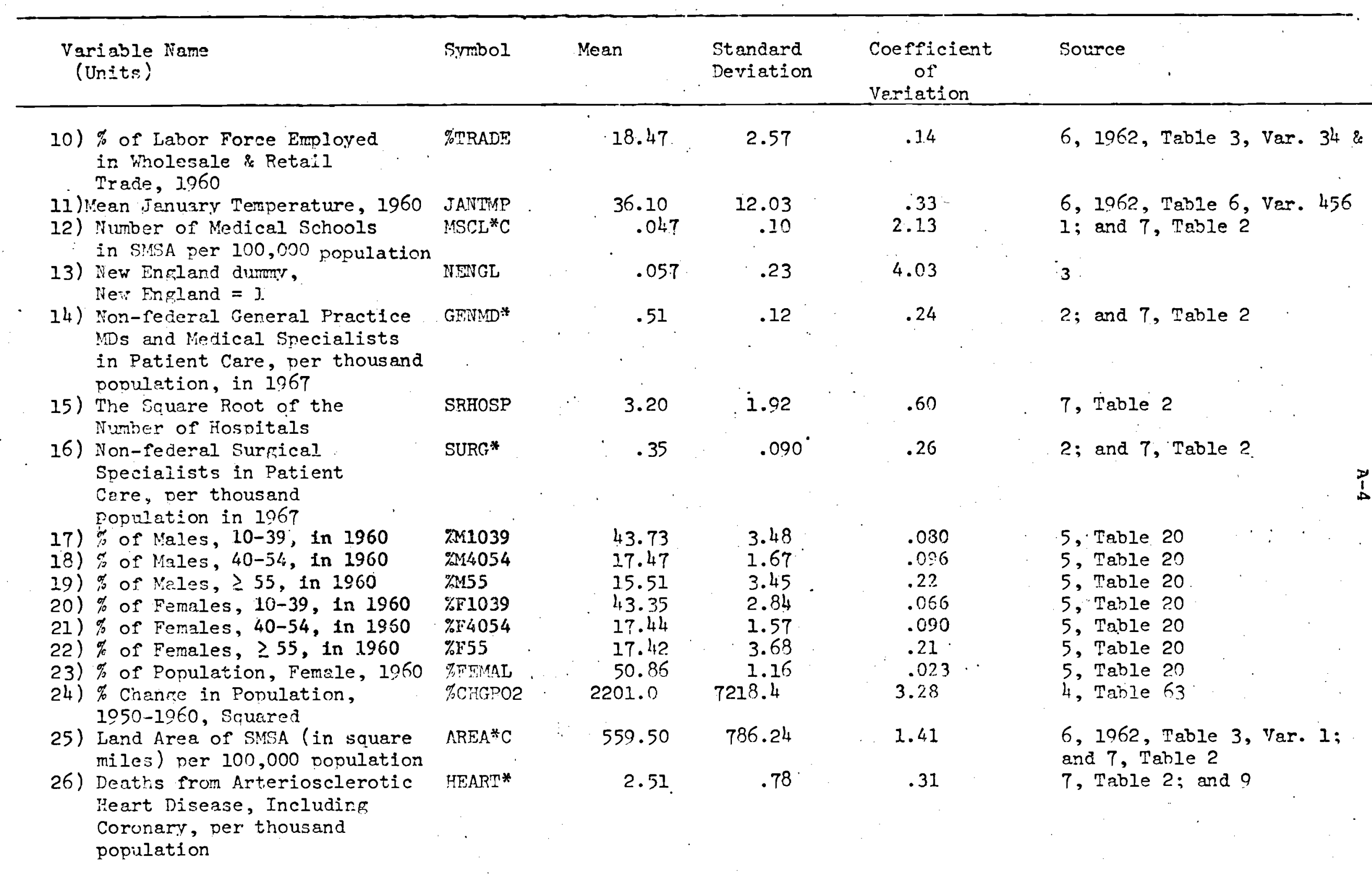


Variable Name

(Units)
Srmbol

\section{Standard \\ Deviation}

Coefficient
of

of
(27) Deaths from Vascular Lesions, STROKF* affecting :Tervous System Strokes per thousand ponulation

(28) Deaths from Motor Vehicle MOTOR* Accidents per thousand nonulation

(29) Deaths from Other Accidents Der thousand nopulation

(30) Suicide ner thousand Donulation

(31) Homicide per thousand nopulation

(32) Deaths from 6 Leading Emergencr situations (Sum of variables (26) to (31))

(33) Insurance $x$ Nunber of Nonsurgical out-of-hosnital Physicians per thousand nonulation ((39) $\times(1.4))$.

(34) Number of Nedical Students ner 100,000 population

(35) Total Deaths per thousand ponulation

(36) Live Births ner 1000 zomen aged $27-46,1.967$

(37) ivubers of Medical Students per Medical School, per 100,000 population ( 0 if schools $=0$ )

(38) Siuare Root of $1 /$ nodulation spop66 1966 (nonulation not in thousands )

\subsection{0}

OTHACC*

SUIC*

HOMIC*

EMERG*

YIT XMD*

MST*C

MOR"

LRR

$\mathrm{ST} / \mathrm{SH}^{*} \mathrm{C}$
.27

.21

.068

.0019

.27

$26.40 \quad 10.58$

14.96

32.53

8.91

1.64

93.81

16.06

12. 98

29.91

.00079
Source

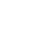

7, Table 2 ; and 9

7, Table 2: and 9

7, Table 2; and ?

7 , Table 2 ; and 9

7, Table 2; and 9

7, Table 2 ; and 9

2; 6, 1967, Table 3, Var. $24,25,58$, and 60 ; and 7 , Table 2

1 ; and 7 , Table 2

7, Table 2 ; and 9

5, Table 20; and 10

1 ; and 7 , Table 2

7, Table 2 
Trble A-2

SOURCES

1. Table 1: "Approved Medical Schools and Schools of Basic "edical Sciences." The Journal of the American "edical Association, Education Number, 210 (Tovember 21,1969$), 1462-3$.

2. Table 14: "Medical Practice Data by Metronolitan Area."

Yaug, J.N. and Roback, G.A. Distribution of Phvsicians, Hosvitals, and Hosnital Peds in the U.S. - 1967 bv Rerion, State, Countr and Metronolitan Area. Chicago: American Medical Association, 1069.

3. U.S. Bureau of the Census' definition of states by region and division.

4. U.S. Department of Commerce, Bureau of the Census.

Census of Ponulation: 1960. Vol. I: Characteristics of the Ponulation. Part $\mathrm{I}$ : United States Summary. Washington, D.C. : U.S. Government Printing Office, 1964.

5. U.S. Department of Commerce, Bureau of the Census. Census of Pooulation: 206n. Vol. I: Characteristics of the Ponulation. Parts II-ITI: [ The states]. Washington, D.C.: U.S. Government Printing office, 1363.

6. U.S. Department of Commerce, Bureau of the Census. County and Citv Data Book(s), 196? and 1967. (A Statistical Abstract Supnlement). lashineton, D.C.: U.S. Government Printing office, 1962 and 1067.

7. U.S. Department of Health, Fducation, and Welfare, Public Health Service. Hosnitals: A Counti and Metronolitan Area Data Book (P!!s Pub. Mo. 204. Section 1). Rockville, Marvland, November 1970.

8. Reed, Louis S. and Carr, Willine. "Private "lealth Insurance, Enrollment, Premiuns and Benefit Fxnense, by Region and State, 1066." Research and Statistics Note No. 14 - 1968, U.S. Dedartment of Vealth, Rducation and Velfare, Social Security Administration, JuJ. 29, 1968.

9. Table 9-9: "Deaths from 59 Selected Causes for Standard Metronolitan. Statistical Areas of the United States: 1960." U.S. Department of Yealth, T.ducation, and Welfare, Public Health Service. Vital Statistics of the United States, 1060 . Vol. II: Nortalitv, Part B. Washinrton, D.C.: U.S. Covernrent Printing office, 1963.

10. Table 1-55: "Iive Births by Live-Birth Order and Race, for SMSA's of the U.S.,1967." U.S. Department of Iealth, Fducation, and "elfare, Public Health Service. Vital Statistics of the United States, 1967. Vol. I: Nrtalitv. Washineton, D.C.: U.S. Government Printing, Office, 1970. 
11. U.S. Department of Comnerce, Bureau of the Census. U.S. Census of Population: 1960. Selected Area Reports. State Economic Areas. Final Report PC (3) -IA. Washington, D.C.: U.S. Government Printing office: 1963. 
Table A-3

Hospital and Surgical Benefits Per Capita

\section{Number of Observations,}

\section{States}

Variable Name

Standard Coefficient

Source for state (units)

Symbol

Mean

Deviation

and SMSA data

A) Endogenous

Variable

1) Hospital and Surgical Bene-

fits per capita

$\mathrm{HSB} / \mathrm{C}$

$41.65 \quad 10.69$

.26

4, Tables $9 ;: 6 ; 1967$;

Tables 1 and 3 ,

Variables 23, 24, 25,58 , and $60 ; 7$, Table 2 ; and 8 .

\section{B) Exogenous}

Variables

1) \% of Employed in 1960, in Manufacturing

\%MNUF

$22.81 \quad 10.14$

.44

6, 1967, Tables 1 in 1960

2) $\%$ of Employed in 1960, White Collar in 1960

\%WC : $\quad 38.92 \quad 4.54 \quad .12$

and 3 , Variables

23 and 24

3) \% of Employed in 1960, in Local Govern\%LOCAL

$6.79 \quad 1.07$ .16 ment in 1962

4) \% of Employed in 1900 , in Federal Government in 1965

5) \% of Population not in an SMSA, in

6,1967 , Tables 1 and 3 ; Variables 23 and 25

6, 1967, Tables 1 and 3 , Varjables 23 and 58

6, 1967, Tables 1 and 3 , Variables 23 and 60

4, Table 18 1960

C) States Excluded: (a) No SilSA's: Vermont, Idaho, Wyoming, and Alaska. (b) Substantial commutation across state borders: New York, New Jersey, Connecticut, Virginia, Maryland, and District of Columbia

D) Welghted Regression (welghted by state's population) $\mathrm{HSB} / \mathrm{C}=-38.992-2.5774(\%$ LOCAL $)+.7215$ (\% MANUF $)+2.1672(\% \mathrm{WC})-1.3556(\% \mathrm{FED})$ 
APPENDIX B - TABLES.

Analysis of SMSA Differences in. Bed Occupancy Rates

Table $B$ - 1 -

Dependent $=$ LnOR

$\mathbf{N}=192$ SMSAS

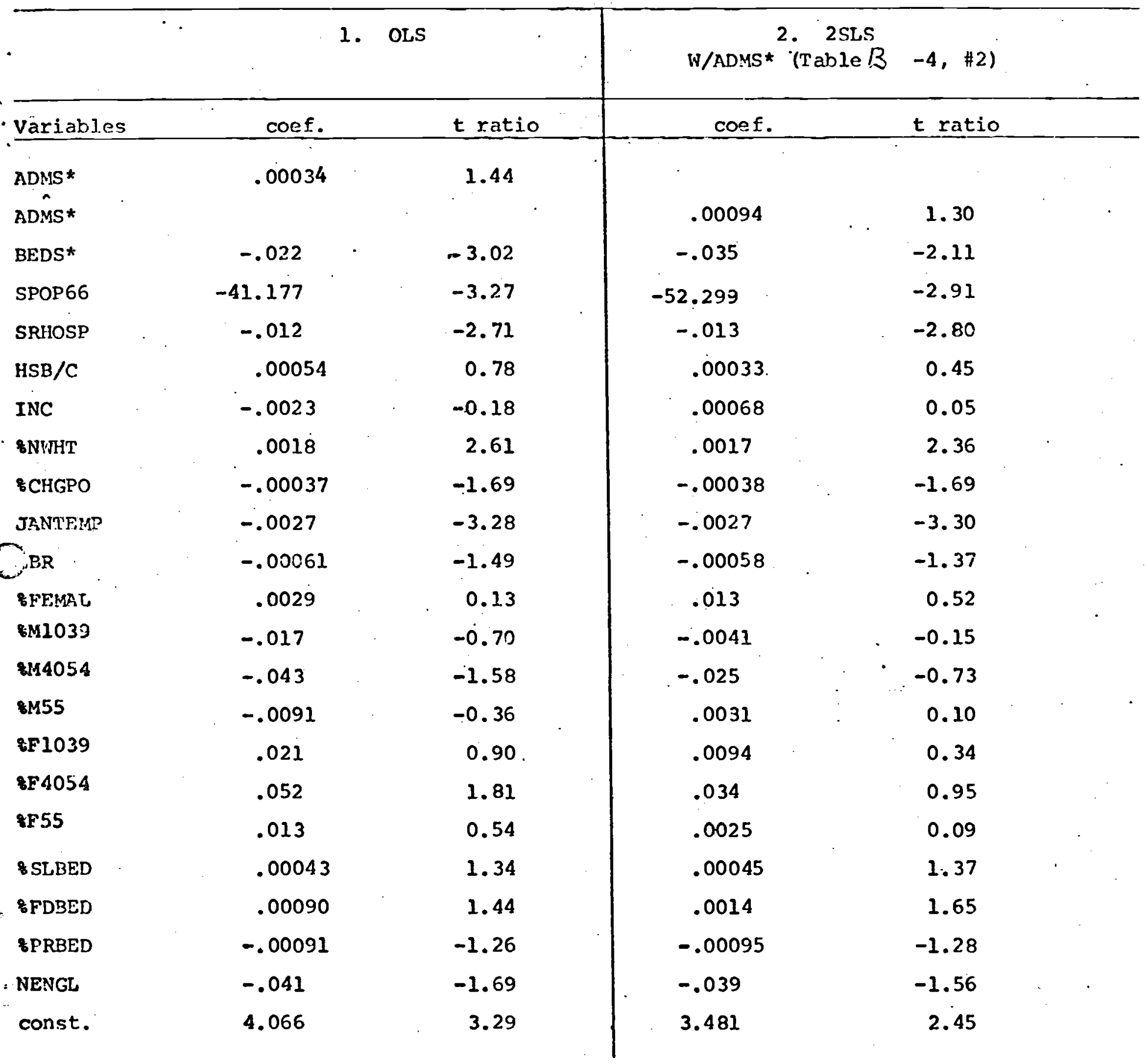

$\mathbf{R}^{2}$ 


$$
\begin{aligned}
& \text { Analysis of SMSA Differences in Bed Occupancy Rates } \\
& \text { Table } B-2- \\
& \text { Dependent }=\text { LnOR } \\
& N=201 \text { SMSAS }
\end{aligned}
$$

\begin{tabular}{|c|c|c|c|c|c|c|}
\hline & & OLS & W/ADMS* & $\begin{array}{l}2 . . \quad 2 S L \\
\text { * Table }\end{array}$ & $-5, \# 2)$ & \\
\hline Variables & coef. & t ratio & coef. & & $t$ ratio & \\
\hline $\begin{array}{l}A D M S^{*} \\
\hat{A} \\
A D^{*} S^{*}\end{array}$ & -.00011 & -0.58 & .00036 & 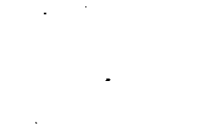 & .070 & \\
\hline Beds* & -.0016 & -0.37 & -.0079 & . & -1.04 & \\
\hline SPOP66 & -34.900 & -2.75 & -46.453 & & -2.70 & \\
\hline SRHOSP & -.012 & -2.75 & -.014 & & -2.89 & \\
\hline $\mathrm{HSB} / \mathrm{C}$ & .00074 & 1.06 & .00063 & & 0.88 & \\
\hline INC & .00010 & 0.008 & .0023 & & 0.17 & \\
\hline \&NIWHT & .0018 & 2.46 & .0016 & & 2.10 & \\
\hline $8 \mathrm{CHGPO}$ & -.00044 & -1.98 & -.00048 & & -2.10 & \\
\hline JANTMP & -.0021 & -2.63 & -.0019 & . & -2.26 & \\
\hline$L B R$ & -.00039 & -0.96 & -.00032 & & -0.76 & \\
\hline GFEMAL & .0097 & 0.46 & .016 & & 0.71 & . \\
\hline $\sin 1746^{\circ}$ & -.0088 & -0.39 & .00074 & & 0.03 & \\
\hline $8 M 4761$ & -.036 & -1.34 & -.020 & . & -0.64 & \\
\hline SMG2 & .0020 & 0.08 & .011 & & 0.43 & . \\
\hline $8 F 1746$ & .017 & 0.76 & .0077 & & 0.31 & \\
\hline $8 F 4761$ & .043 & 1.53 & .028 & & 0.85 & \\
\hline $8 F 62$ & .0044 & 0.19 & -.0040 & & -0.16 & \\
\hline \&SIBBED & .00043 & 1.36 & .00050 & & 1.53 & \\
\hline \&FDBED & .00046 & 0.82 & .00072 & & 1.14 & \\
\hline \&PRBED & -.0013 & -1.70 & -.0013 & & -1.77 & \\
\hline NENGL & -.031 & -1.29 . & -.027 & & -1.07 & \\
\hline const. & 3.448 & 3.05 & 3.113 & & 2.61 & \\
\hline
\end{tabular}




$$
\begin{aligned}
& \text { Analysis of SMSA Differences in Bed Occupancy Rates } \\
& \text { Table } B-3- \\
& \text { Dependent }=\text { LnOR } \\
& N=192 \text { SMSAs }
\end{aligned}
$$

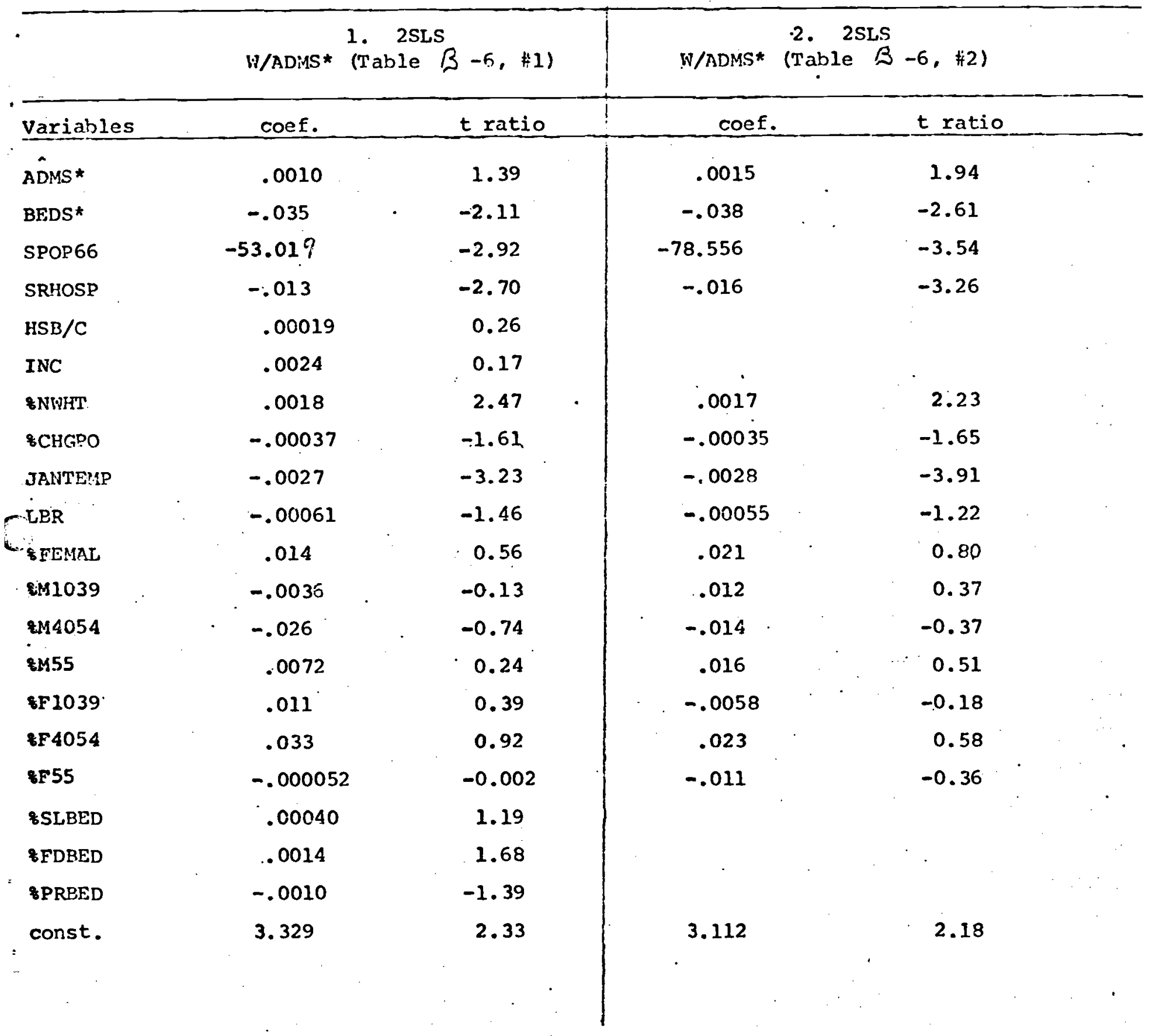


